\title{
Persistent thermally driven shift in the functional trait structure of herbivorous fishes: Evidence of top-down control on the rebound potential of temperate seaweed forests?
}

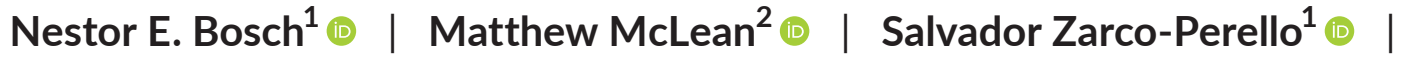

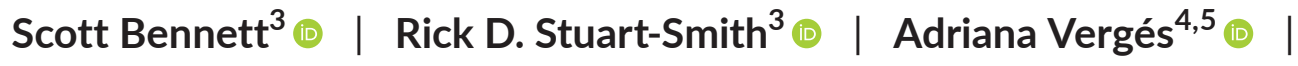

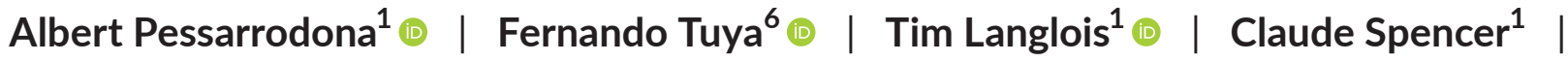

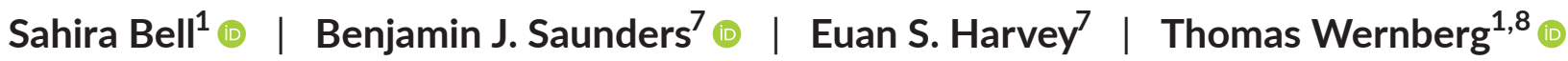 \\ ${ }^{1}$ The UWA Oceans Institute, School of Biological Sciences, The University of Western Australia, Crawley, Western Australia, Australia \\ ${ }^{2}$ Department of Biology, Dalhousie University, Halifax, Nova Scotia, Canada \\ ${ }^{3}$ Institute for Marine and Antarctic Studies, University of Tasmania, Hobart, Tasmania, Australia \\ ${ }^{4}$ Centre of Marine Science \& Innovation, Evolution \& Ecology Research Centre, School of Biological, Earth \& Environmental Sciences, UNSW Sydney, \\ Kensington, New South Wales, Australia \\ ${ }^{5}$ Sydney Institute of Marine Science, Mosman, New South Wales, Australia \\ ${ }^{6}$ Grupo en Biodiversidad y Conservación, IU-ECOAQUA, Universidad de Las Palmas de G.C., Canary Islands, Spain \\ ${ }^{7}$ School of Molecular and Life Sciences, Curtin University, Bentley, Western Australia, Australia \\ ${ }^{8}$ Institute of Marine Research, His, Norway
}

\section{Correspondence}

Nestor E. Bosch, The UWA Oceans Institute, School of Biological Sciences, The University of Western Australia, 35 Stirling Highway, Crawley 6009, WA, Australia.

Email: nbosch1989@gmail.com

Funding information

Ecological Society of Australia Holsworth

Research Endowment, Grant/Award

Number: RA/1/411/101; Australian

Government International Research

Training Program; the Robson \&

Robertson UWA PhD awards; the Sea

World Research \& Rescue Foundation,

Grant/Award Number: SWR/14/2019;

the Australian Research Council,

Grant/Award Number: DP170100023

and DP190100058; Hermon Slade

Foundation, Grant/Award Number:

HSF13/13

\begin{abstract}
Extreme climatic events can reshape the functional structure of ecological communities, potentially altering ecological interactions and ecosystem functioning. While these shifts have been widely documented, evidence of their persistence and potential flow-on effects on ecosystem structure following relaxation of extreme events remains limited. Here, we investigate changes in the functional trait structure - encompassing dimensions of resource use, thermal affinity, and body size - of herbivorous fishes in a temperate reef system that experienced an extreme marine heatwave (MHW) and subsequent return to cool conditions. We quantify how changes in the trait structure modified the nature and intensity of herbivory-related functions (macroalgae, turf, and sediment removal), and explored the potential flow-on effects on the recovery dynamics of macroalgal foundation species. The trait structure of the herbivorous fish assemblage shifted as a result of the MHW, from dominance of coolwater browsing species to increased evenness in the distribution of abundance among temperate and tropical guilds supporting novel herbivory roles (i.e. scraping, cropping, and sediment sucking). Despite the abundance of tropical herbivorous fishes and intensity of herbivory-related functions declined following a period of cooling after the MHW, the underlying trait structure displayed limited recovery. Concomitantly, algal assemblages displayed a lack of recovery of the formerly dominant foundational species, the kelp Ecklonia radiata, transitioning to an alternative state dominated by
\end{abstract}


turf and Sargassum spp. Our study demonstrates a legacy effect of an extreme MHW and exemplified the value of monitoring phenotypic (trait mediated) changes in the nature of core ecosystem processes to predict and adapt to the future configurations of changing reef ecosystems.

\section{KEYWORDS}

ecosystem resilience, herbivory, marine heatwaves, ocean warming, trait-based ecology, tropicalization

\section{1 | INTRODUCTION}

Globally, terrestrial and marine taxa are shifting their geographical ranges in response to climate warming (Lenoir \& Svenning, 2015). Rapid shifts in temperature isotherms (Burrows et al., 2011) and increased frequency and intensity of discrete warming events (i.e. marine heatwaves, MHWs; Oliver et al., 2018) are expected to cause profound biological reorganizations (Pecl et al., 2017; Smale et al., 2019). This phenomenon challenges current management frameworks aimed at sustaining the livelihoods of millions of people that rely on natural resources by maximizing contemporary biodiversity and ecosystem functioning (Bonebrake et al., 2018). Despite many species being expected to track their thermal niche (Parmesan \& Yohe, 2003; Poloczanska, 2013), lags in species responses can arise due to the complex interplay between evolutionary, demographic, and ecological processes that underpin range shift dynamics (Bates et al., 2014; Stuart-Smith et al., 2021). This can ultimately result in the formation of novel assemblages with altered biotic interactions that can cascade through entire food webs (Albouy et al., 2014; Blois et al., 2013).

While ecologists have largely focused on documenting and predicting climate-driven changes in biodiversity (Blowes et al., 2019; Molinos et al., 2016), understanding and forecasting changes in species interactions and their implications for ecosystem functions is far more challenging (Gilman et al., 2010). This is particularly the case for marine ecosystems, where there is scarce information on the myriad of trophic links (Parravicini et al., 2020). Decades of small-scale experimental manipulations (e.g. Duffy \& Emmett Duffy, 2009), coupled with recent observational evidence across complex natural ecosystems (e.g. Brandl et al., 2019; Lefcheck et al., 2019), have demonstrated the importance of biodiversity for enhancing ecosystem functioning. However, biodiversity is a complex multidimensional term (Bosch et al., 2017; Mcgill et al., 2015), and commonly used metrics, such as species richness, may mask key structural changes that ultimately shape the nature, extent, and intensity of ecosystem functions (Hillebrand et al., 2018). This is exemplified in marine systems, where changes in the identity and abundance of consumers along spatial environmental gradients can determine rates of primary and secondary consumption (Ruttenberg et al., 2019; Whalen et al., 2020). Because species richness can remain stable despite marked changes in species composition (Dornelas et al., 2014), it is key to understand the identities and characteristics of those species being replaced or added to local assemblages (Blowes et al., 2019; Lefcheck et al., 2021; Magurran et al., 2015).

A key limitation of taxonomic (i.e. species based) approaches is that they fail to provide generalizable rules that can be applied across different geographies with markedly different species compositions. In this context, ecologists have long recognized that species sharing certain morphological, behavioural, or physiological features (i.e. traits) are ecologically and functionally more similar (Cadotte et al., 2013), and it is these similarities in species traits that shape species niches (Mcgill et al., 2006; McLean et al., 2021), interactions (Fortunel et al., 2016), and contributions to ecosystem functioning (Gagic et al., 2015). Because traits are intrinsically linked to the performance of organisms (Violle et al., 2007), chronic or acute disturbances are expected to modify the identity, range, and variability of organismal traits (Mouillot et al., 2013). Unsurprisingly, changes in functional trait identity and structure have been widely reported in marine ecosystems as a response to gradual ocean warming and MHWs, for taxa ranging from fishes (e.g. McLean et al., 2018), corals (e.g. Gómez-Gras et al., 2021), and multitrophic communities (e.g. Törnroos et al., 2019). This functional restructuring has the potential to impair key ecosystem processes, such as nutrient cycling, biomass production, and consumer-resource interactions (Brandl et al., 2019; Mouillot et al., 2011). However, few studies provide empirical evidence between changes in the identity and structure of functional traits and quantitative measures of realized ecosystem functions (e.g. predation, bioerosion, herbivory) that ultimately underpin ecosystem productivity and services such as food provisioning (Bellwood et al., 2018; Tebbett et al., 2021).

Fish herbivory is a key ecological process in the tropics, mediating the health of coral reefs through trophic control on macroalgae (Hughes et al., 2010). In contrast, fish herbivores typically play a more limited role in controlling macroalgal cover on reefs in most temperate regions (Steneck et al., 2017). Across many tropicaltemperate transition zones globally, tropical herbivorous fishes are rapidly expanding their ranges in response to global warming a phenomenon more broadly known as 'tropicalization' (Vergés, Steinberg, et al., 2014). Phenotypic, trait-mediated (e.g. morphological and behavioural), differences between native temperate and range-expanding tropical herbivorous fishes can fundamentally shift the nature of herbivore-algae interactions (i.e. 'how' they do it; e.g. scraping, cropping, sediment sucking), altering the rates of macroalgal consumption (Zarco-Perello et al., 2020; Zarco-Perello et al., 
2017) and undermining the resilience of ecologically and economically valuable seaweed forests (Bennett et al., 2015; Vergés et al., 2016). Understanding the temporal dynamics of this part of the 'tropicalization' process is a key challenge for managing transitioning temperate reefs in the Anthropocene (Vergés et al., 2019). However, we still have a limited knowledge on the relative persistence of these climate-driven functional reorganizations once environmental conditions return to historical states, and their potential flow on effects on the recovery dynamics of macroalgal foundation species.

Here, we address this knowledge gap using a 10-year dataset of herbivorous fishes, benthic habitat structure, and quantitative measures of herbivory-related functions (i.e. macroalgae, turf, and sediment removal) in a warm-temperate region affected by an extreme MHW and the subsequent return to cooler conditions. We used a trait-based approach to explore how the identity and structure of herbivorous fish functional traits - encompassing dimensions of resource use, thermal affinity, and body size - have changed over time. First, we hypothesized that the rapid arrival and demographic explosion of tropical fishes following the onset of the 2011 MHW would alter the trait structure, shifting dominance from cool-water browsing species towards warm-affinity species with diverse traits that play novel herbivory functions (i.e. scraping, cropping, sediment sucking). Second, although we expected that the abundance of tropical species and the intensity of herbivory-related functions would decline following the return to cooling conditions, we aimed to investigate whether any persistence of tropical species at expanding range-edges over decadal scales could still contribute to a 'legacy effect' of the MHW on the functional structure of herbivorous fishes and recovery dynamics of benthic foundational species.

\section{2 | METHODS}

\section{1 | Study context}

This study was conducted in a temperate-tropical transition zone (Port Gregory; $28.2^{\circ} \mathrm{S}, 114.2^{\circ} \mathrm{E}$ ), located in the Midwest bioregion of south-western Australia (Figure 1a). Sea surface temperatures in the region are strongly influenced by the strength and advection of the Leeuwin Current (Feng et al., 2008), a poleward-flowing warm current that transports tropical propagules into temperate latitudes (Pearce et al., 2011). Variability in 'El Nĩno' Southern Oscillation in the Pacific ocean modulates the magnitude of warming ('La Niña' events) and cooling ('El Niño' events) phases (Zinke et al., 2014), during which periods of anomalously warm (i.e. marine heatwaves, MHWs) and anomalously cool (i.e. marine cold spells, MCSs) temperatures may be observed, respectively. During the 2010-2011 austral summer, an unprecedented extreme MHW caused sea temperatures to soar $\sim 4^{\circ} \mathrm{C}$ above the summer maxima (Figure $1 \mathrm{~b}$; Methods S1; Table S1a; Wernberg et al., 2013). Subsequent anomalously warm summers compounded the widespread ecological impacts of the MHW, with the dominant habitat-forming kelp (Ecklonia radiata) collapsing across $>100 \mathrm{~km}$ of its northern distributional range (Wernberg et al.,
2016). The influx and enhanced survival of tropical herbivorous fishes following the MHW further contributed to the maintenance of an alternate state dominated by low-lying, fast-growing, turf algae (Bennett et al., 2015). In recent years, sea surface temperatures have returned to cooler conditions, characterized by the onset of a cooling phase (2015-2016 'El Niño' event) and the presence of several MCSs (Figure 1c; Table S1b), which have enabled the recovery of some cool-water species of commercial interest (Feng et al., 2021).

To capture the dynamics in temperature regimes in the region, we stratified our sampling in three time periods, corresponding to a historical baseline of cool-water conditions (i.e. pre-heatwave), a pulse heating event and subsequent warm-years (i.e. post-heatwave), and a return to cooler conditions coupled with the presence of MCSs (i.e. post-cooling). Sampling was conducted on four sites (i.e. reefs), consisting of wave exposed, shallow (5-10 m depth), sandstone reef platforms, located $\sim 0.5-1.3 \mathrm{~km}$ from the coast and separated by at least $\sim 1 \mathrm{~km}$ (Figure 1a).

\subsection{Fish and benthic surveys}

Fish and benthic assemblages were censused using diver operated stereo-video surveys (stereo-DOV), conducted between April and June in 2006, 2013, 2017, 2018, and 2019. At each site, 8-12 stereoDOV transects $\left(25 \times 5 \mathrm{~m} ; 125 \mathrm{~m}^{2}\right)$ were surveyed by a SCUBA diver swimming at a constant pace ( 2 min per transect), with the cameras angled slightly downward, at $\sim 50 \mathrm{~cm}$ above the bottom, to enable the seafloor structure and composition to be observed throughout the video. Detailed explanations of standard field operating procedures, system configuration, and calibration of cameras are provided in Goetze et al. (2019). All surveys were conducted during daylight hours ( $\sim 9$ am to $5 \mathrm{pm}$ ) and replicated transects were spaced by at least $10 \mathrm{~m}$ to minimize non-independence of fish counts. Trends in benthic habitat structure were analysed for all the survey years, while fish data were analysed through the three time periods: preheatwave (2006), post-heatwave (2013), and post-cooling (2017 and 2019). For analyses of trait spaces and functional dissimilarities (see below), we carried out a resampling procedure to control for the potential effect of varying survey effort on the range and variability of trait values in the pool of species for each period. At each site, eight transects (i.e. minimum effort at a site in any single year) were randomly sampled, with replacement. We repeated this procedure 99 times, and then computed the average density of each species, at each site, for each time period. This also enabled us to minimize the bias associated with the low detectability of schooling, roving, herbivorous fishes in diver visual censuses at a single time point (Fox $\&$ Bellwood, 2008).

The video footage obtained from the stereo-DOV was analysed in 'EventMeasure' (SeaGIS Pty Ltd). All fishes were identified to the lowest taxonomic level possible, and their fork length measured (nearest $\mathrm{mm}$ ). We pooled sister species with high morphological similarity for the analyses, as the limited visibility and distance to the cameras prevented their taxonomic identification. Specifically, we 
(a)

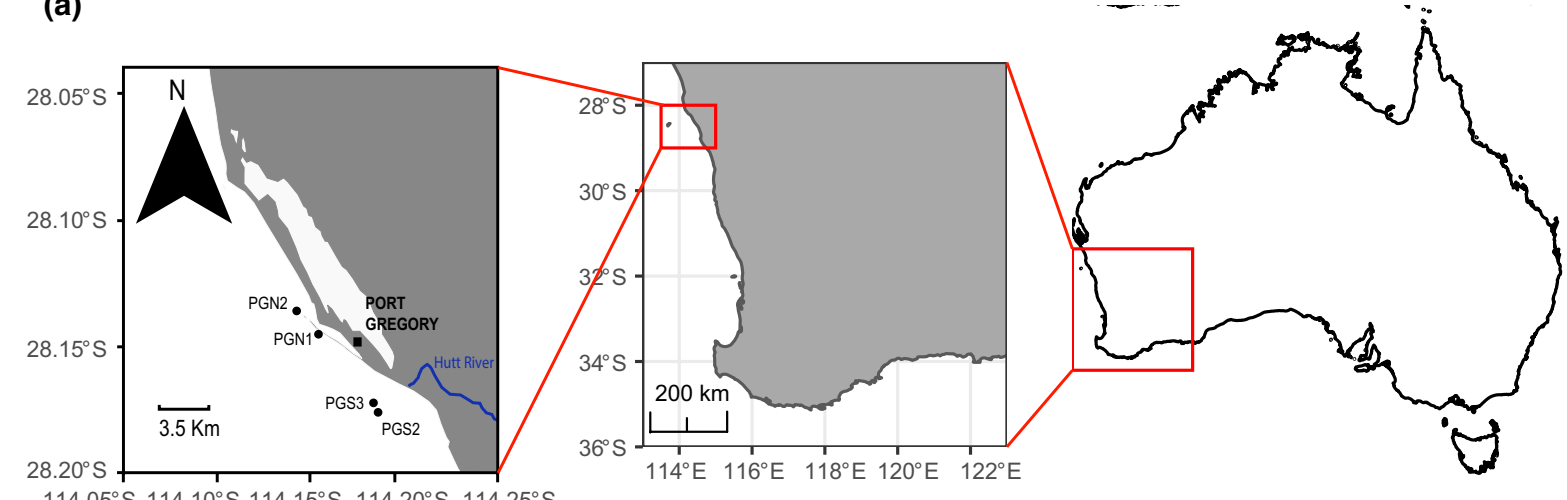

$114.05^{\circ} \mathrm{S} 114.10^{\circ} \mathrm{S} 114.15^{\circ} \mathrm{S} 114.20^{\circ} \mathrm{S} 114.25^{\circ} \mathrm{S}$

(b) Post-heatwave (2011-2014)

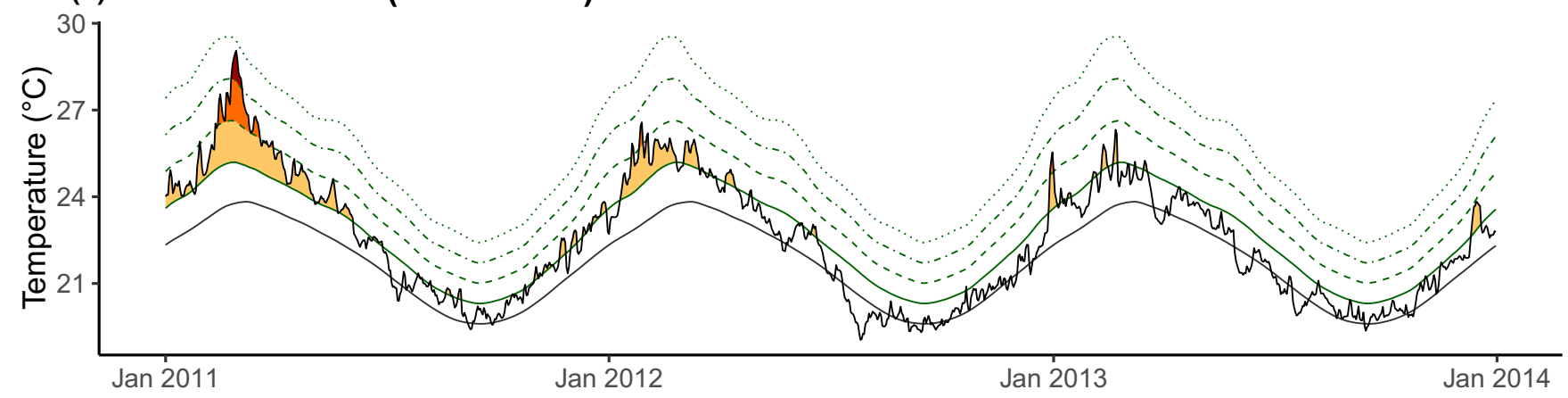

(c) Post-cooling (2016-2020)

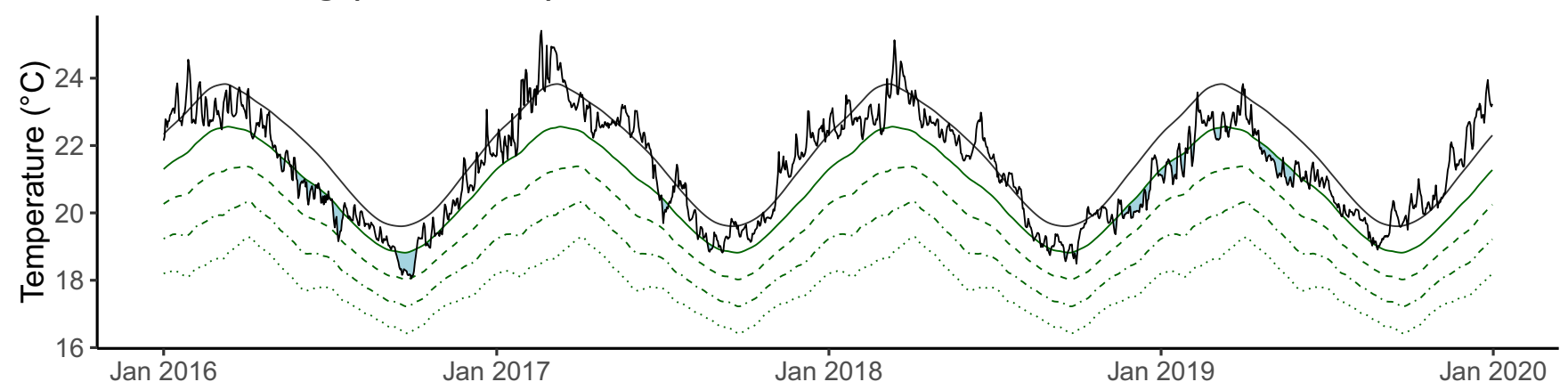

- Temperature - Climatology $\quad$ Threshold $\quad$ - 2x Threshold - - 3x Threshold . . . 4x Threshold

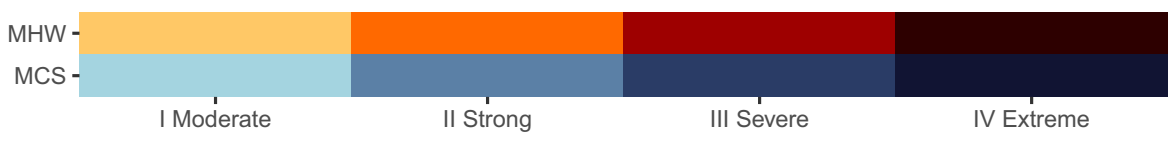

FIG URE 1 (a) Map of the study location (Port Gregory, $28^{\circ}$ latitude) in the Midwest bioregion of south-western Australia. Dark dots indicate the distribution of study sites $(n=4)$. (b, c) Trends in daily sea surface temperature (SST, ${ }^{\circ} \mathrm{C}$; solid black line) during the (b) postheatwave (2011-2014) and (c) post-cooling period (2016-2020). The solid continuous black line represents the seasonal climatology (longterm mean), and the green lines represent the thresholds to typify marine heatwaves (MHWs) and marine cold spells (MCSs; Methods S1). Colour palette illustrates the MHWs and MCSs categories

pooled the tropical chub Kyphosus bigibbus with temperate drummers Kyphosus sydneyanus and Kyphosus gladius, and the tropical pomacentrids Pomacentrus milleri and Stegastes obreptus. In addition, Scarus ghobban and Scarus schlegeli were often not distinguishable, and these species were also pooled for the subsequent analyses. We examined benthic biogenic habitat by pausing the stereo-DOV footage every $10 \mathrm{~s}(\sim 2 \mathrm{~m} ; n=10$ replicates per transect) and quantifying the percent cover within a $1 \mathrm{~m}^{2}$ area of the image where the benthos was visible. Benthic sessile biota was classified in the main morphofunctional groups for the study region (Bennett et al., 2015): kelp (Ecklonia radiata), other canopy (mainly Sargassum spp.), and turf. Turfs were defined as single- or multi-species aggregations of lowlying algae ( $<2 \mathrm{~cm}$; Connell et al., 2014), that form a conglomerate with detrital material, cyanobacteria and seaweed germlings. Other 
benthic groups with extremely low coverage through years (e.g. hard corals) were excluded from the analyses.

\subsection{Shifts in the trait identity of the herbivorous fish assemblage}

We defined herbivorous fishes as any fish that removes algal material independently of the nutritional resource targeted (e.g. algae, detritus, and cyanobacteria). Each herbivorous fish was assigned to a functional group based on their herbivory-related function (i.e. 'what' function): macroalgal, turf, and/or sediment removal (Bellwood et al., 2018), and phenotypic traits (e.g. morphological and behavioural) that determine how they access that resource (i.e. 'how' function): browsers (i.e. species targeting large erect macroalgae, as well as their germlings within the turf), scrapers (i.e. species that remove portions of the turf while targeting cyanobacteria), excavators (i.e. species that remove turf and underlying reef matrix while targeting cyanobacteria), algal farmers (i.e. species that farm diverse and productive stands of filamentous algae within small, defended, territories), and detritus suckers (i.e. species that suction detritus from turfs) (Table S2; Siqueira et al., 2019). Species known to display functional plasticity in the study system (e.g. rabbitfish and parrotfishes; Bennett et al., 2015) were allowed to contribute to more than one herbivory-related function.

Functional groups of herbivores were subsequently mapped in a two-dimensional trait space, along axes of thermal affinity $\left({ }^{\circ} \mathrm{C}\right)$ and body size (cm). Thermal affinity and body size were selected as they are linked to changing ecosystem functions in a climate change context. For instance, the response of fish species to temperature changes can be described with a reasonable predictive capacity by their thermal affinity (Burrows et al., 2019; Day et al., 2018), while body size can relate to range size and in some cases to range shift potential (Luiz et al., 2013). On the other hand, changes in body size structure can alter rates of ecological processes such as herbivory (Shantz et al., 2019). Thus, although we considered body size alongside thermal affinity as a 'response trait' to describe the changing functional structure of herbivorous fishes in relation to environmental change, it could also be considered an 'effect trait'. We primarily considered the ecological effects of changes in functional structure through the experimental component of the study, however, rather than solely on the basis of shifts in trait structure. Thermal affinity was defined as the midpoint between the 5th and 95th percentiles of each species' realized thermal niche, obtained from a larger dataset (Stuart-Smith et al., 2015). Body size was defined as the species modal length (i.e. most frequent, $\mathrm{cm}$ ) at each time period, obtained from stereo-DOVs, to account for interannual differences in population size structure in the analyses. We assigned average trait values to morphologically similar conspecifics that were not identified to species level in the stereo-DOVs (Kyphosus spp., Pomacentrus spp., and Scarus spp.).

We investigated changes in the distribution of species and density of fish individuals ( $\log x+1$ transformed) in the two-dimensional trait space through time periods, by computing the abundance-weighted community-level mean trait values (CWM thermal affinity and CWM body size) in the 'FD' R package (Laliberté et al., 2014). To evaluate how the overall mass of the herbivorous fish assemblage shifted through time periods, we additionally calculated the 50\%, 75\%, and $95 \%$ highest density intervals of each trait distribution in the 'HDInterval' R package (Meredith \& Kruschke, 2016), and plotted this in the twodimensional trait space via a kernel density estimator in the 'MASS' R package (Venables \& Ripley, 2002). The highest density interval refers to the range of the trait distribution with the highest probability mass, and therefore represents the range of trait values that are most frequent within the community. Unlike symmetrical density intervals (e.g. quantiles), HDI gives intervals at which all the points have a higher probability density than those outside (Meredith \& Kruschke, 2016), being more suitable for skewed or multimodal distributions, as those found here for the traits considered.

\subsection{Shifts in the taxonomic and functional structure of the herbivorous fish assemblage}

Temporal changes in taxonomic and functional structure of the herbivorous fish assemblage were investigated using an attribute diversity framework, based on generalizations of Hill numbers (Chao et al., 2014). Beta diversity was calculated as normalized Sørensen pairwise dissimilarities, which range from 1 when two assemblages do not share any taxonomic (i.e. species) and/or functional entities to 0 , when all taxonomic and/or functional entities are shared. Functional entities (i.e. functional groups) were defined as all the species within a specified threshold value of functional distinctiveness (Chao et al., 2019); here, the averaged (0.63) trait dissimilarities between species in a Gower distance matrix based on species herbivore guild (i.e. 'how' function), thermal affinity $\left({ }^{\circ} \mathrm{C}\right)$, and body size $(\mathrm{cm})$ (Table S3). Within this framework, Sørensen dissimilarities are expressed as a function of a parameter ' $q$ ', which controls the sensitivity of the metric to species' and/or functional entities' relative abundances (Chao et al., 2019). When ' $q$ ' $=0$, dissimilarities are insensitive to changes in abundance structure (i.e. analogous to an occurrence-based approach), while increasing ' $q$ ' (i.e. ' $q$ ' > 0) places more weight on the distribution of abundances among rare, common, and dominant entities. This enabled us to test whether changes in taxonomic and functional structure were mostly driven by the addition or loss of species' and/or functional entities' or changes in abundance structure. Prior to analyses, we converted raw abundances to relative abundance to give equal weight to assemblages through time periods. Analyses were carried out in $\mathrm{R}$ using functions in the ' $m F D^{\prime} \mathrm{R}$ package (Magneville et al., 2021).

\section{5 | Quantifying herbivory}

We quantified two herbivory processes that are key to maintaining turf-dominated states in this system: kelp (Ecklonia radiata) browsing 
rates and turf grazing rates. Herbivory was measured in November 2013 and November 2019, corresponding to the post-heatwave and post-cooling periods, respectively, with herbivory data from 2013 sourced from Bennett et al. (2015). Averaged daily sea surface temperature, obtained from the NOAA OISST data (Reynolds et al., 2007), was comparable between the two time periods (range $=21.5^{\circ} \mathrm{C}-22.1^{\circ} \mathrm{C} ; 21.78^{\circ} \mathrm{C} \pm 0.18^{\circ} \mathrm{C}$, mean $\pm \mathrm{SD}$ ). Two reefs were sampled per year, corresponding to a subset of the reefs for which fish and benthic surveys were conducted, with experimental and video assays deployed within the typical feeding time frame of diurnal herbivorous fishes ( 8 am to 4 pm; Fox et al., 2009).

To estimate consumption on the kelp Ecklonia radiata, we translocated adults and recruits from populations where kelp cover did not collapse after the 2011 marine heatwave (Wernberg et al., 2016), following experimental protocols described in Bennett et al. (2015). All individuals were collected whole, with the holdfast intact, and were individually weighed, measured (thallus length, $\mathrm{cm}$ ), and tagged. To minimize manipulation-related stress, individuals were stored in cool damp calico bags and kept in dark conditions at all times. Each individual was attached to a weight and haphazardly placed on the studied reefs within $24 \mathrm{~h}$ of collection, with each replicate separated by at least $5 \mathrm{~m}$ from each other. For each time period, we measured the individual biomass remaining $(\mathrm{g})$ in each adult and kelp individual translocated, at each site at $24 \mathrm{~h}$ intervals, for a maximum of $48 \mathrm{~h}$, which corresponded to the time total kelp consumption was observed in 2013. Individuals that presented bleaching marks, indicative of stress, after the initial $24 \mathrm{~h}$ period were excluded from the analyses. Loss of kelp biomass due to factors other than herbivory has been found to be negligible in this system within the timeframes kelp individuals were deployed (Bennett et al., 2015). We note tissue damage due to algal manipulation might affect the grazing intensity observed, but we make the assumption that such an effect would be consistent between periods, and thus this systematic bias should not cofound the comparison between periods.

To quantify the contribution of each herbivorous fish to kelp and turf consumption, we haphazardly deployed video cameras (GoPro Hero $3+$ ) on each reef. For kelp consumption, we filmed three replicate kelp adults at each site, within each $24 \mathrm{~h}$ period. For turf grazing rates, we filmed three replicate $2 \mathrm{~m}^{2}$ patches of turf-dominated reef at each site, for four to five consecutive days. In both cases, the duration of the video assays varied between $1 \mathrm{~h}$ and $3.5 \mathrm{~h}$, depending on factors that constraint the battery life of the video cameras $(2.15 \mathrm{~h} \pm 0.71 \mathrm{~h}$, mean $\pm S D$, for kelp browsing rates; $1.97 \mathrm{~h} \pm 0.59 \mathrm{~h}$, mean $\pm S D$, for turf grazing rates). Feeding rates on kelp transplants and turf were analysed in 'EventMeasure' (SeaGIS Pty Ltd), by counting all the bites for each fish species and dividing by the duration of the video replicate. Counts of bites were performed 2 min after all human activity ceased in the field of view, with bites considered as any time a fish struck the benthos with its jaw opened (Hoey \& Bellwood, 2009). To account for the positive influence of body size in the amount of material removed per bite (Longo et al., 2014), we first converted the species-specific modal length at each time period to biomass, using published length-weight relationships (Froese \&
Pauly, 2012). Then, mass standardized bite rates were computed by multiplying standardized bite rates by the population modal biomass (expressed as $\mathrm{kg}$ bites $/ \mathrm{m}^{2} \mathrm{~h}$ for turf; and $\mathrm{kg}$ bites/h for kelp). Unlike stereo-DOV, the close proximity of feeding observations to the cameras enabled us to decouple the relative contribution of morphologically similar species with distinct thermal affinities (e.g. Kyphosus spp.) to patterns of herbivory.

\section{6 | Statistical analyses}

We used linear models to test whether the magnitude of taxonomic and functional dissimilarities varied through pairs of time periods: pre-heatwave to post-heatwave, pre-heatwave to post-cooling, and post-heatwave to post-cooling. Linear models were developed independently for each ' $q$ ' parameter (i.e. ' $q$ ' $=0,1$, and 2 ). To minimize the probability of Type I error due to non-independence of sample sites within periods, we reduced the significance level $(\alpha)$ to 0.01 .

We tested for changes in the intensity of macroalgae, turf, and sediment removal by analysing (a) changes in the abundance of herbivorous fishes, (b) changes in kelp browsing rates, and (c) changes in turf grazing rates. For each response metric, we first aggregated (summed) the abundances and bite rates of fish species potentially contributing to each herbivory-related function (Table S2). Additionally, we partitioned the contribution of herbivorous fishes by their thermal guild, defined as temperate $\left(<23^{\circ} \mathrm{C}\right)$ and tropical $\left(>23^{\circ} \mathrm{C}\right)$ based on a naturally occurring separation in thermal affinity observed across continents (Stuart-Smith et al., $2015,2017)$. We used generalized linear mixed models (GLMMs) to test whether observed differences in herbivory-related functions through time periods varied between temperate and tropical guilds (two-way interaction, 'time period $\times$ thermal guild'). Likewise, we tested whether rates of consumption in adult and juvenile kelp transplants differed between post-heatwave and post-cooling periods (two-way interaction, 'hour $\times$ time period'). All models were implemented in the 'glmmTMB' R package (Brooks et al., 2017) for each herbivory-related function and kelp life-history stage separately, with $p$-values obtained via a likelihood ratio test. Abundance models were developed with a 'negative binomial' distribution, while bite rates and kelp consumption were fitted using a 'Tweedie' error family. Site was used as a random effect to account for spatial variation in unmeasured factors that might affect herbivory. The day of sampling was also included as an independent random effect in models of bite rates and kelp consumption to account for repeated measures (within subject effect). All models were inspected for violations of statistical assumptions in the 'DHARMa' R package (Hartig, 2017). We additionally estimated the relative contribution (\%) of each herbivore functional group (i.e. 'how' function) within each thermal guild to patterns of (a) herbivorous fish abundance, (b) kelp browsing rates, and (c) turf grazing rates through time periods to visualize changes in the identity of the main herbivore functional groups contributing to changing herbivory-related functions. The data and $\mathrm{R}$ code used for analyses can be found at the 
author GitHub repository (https://github.com/NestorBosch/Herbi vory_Trait_Structure; Bosch, 2021).

\section{3 | RESULTS}

\subsection{Shifts in trait identity}

We found marked shifts in the trait identity of the herbivorous fish assemblage following the 2011 MHW (Figure 2b,c). Before the $2011 \mathrm{MHW}$, the overall mass of the assemblage was concentrated on cooler affinity browsing species (Kyphosus spp.; $50 \%$ $\mathrm{HDI}=20.5^{\circ} \mathrm{C}-22.2^{\circ} \mathrm{C}$, Table S4a). After the MHW, the increased abundance of pre-established warm-affinity species (the browsing rabbitfish, Siganus fuscescens; the scraping parrotfishes, Scarus spp.; and the algal farmers Stegastes obreptus and Pomacentrus milleri), coupled with the influx of novel warm-affinity functional groups (the sediment sucker Acanthurus grammoptilus; Figure S1a,b), resulted in a shift of the assemblage centroid from $22.1^{\circ} \mathrm{C}$ to $23.4^{\circ} \mathrm{C}$ (Table $\mathrm{S} 4 \mathrm{a})$. However, the abundance of the majority of cooler-affinity species, with the exception of the browser Olisthops cyanomelas, which became locally extinct, remained remarkably stable (Figure S1a,b). This resulted in the formation of two modes along the thermal affinity axis (Figure 2b), whereby the mass of the assemblage was more evenly distributed among a diverse suite of temperate and tropical species $\left(50 \% \mathrm{HDI}=20.5^{\circ} \mathrm{C}-22.2^{\circ} \mathrm{C}\right.$ and $24.7^{\circ} \mathrm{C}-26.1^{\circ} \mathrm{C}$, Table S4a). After periods of recent cooling, we found that the abundance of most warm-affinity species had declined (Figure S1c), but the thermal structure remained relatively stable; the community centroid and the second mode characterizing tropical species only retracted slightly (Figure $2 \mathrm{~d} ; \mathrm{CWM}=23.1^{\circ} \mathrm{C} ; 50 \% \mathrm{HDI}=20.3^{\circ} \mathrm{C}-22.1^{\circ} \mathrm{C}$ and $25^{\circ} \mathrm{C}-25.9^{\circ} \mathrm{C}$; Table S4a).

Trends along the body size axis were less marked, although the assemblage became progressively dominated by smaller-bodied herbivores (Figure 2; CWM pre-heatwave $=27.9 \mathrm{~cm}$, CWM postheatwave $=26.2 \mathrm{~cm}, \mathrm{CWM}$ post-cooling $=22.4 \mathrm{~cm}$ ). Importantly, changes in population size structure were highly species specific, with the majority of species remaining relatively invariant, while the population modal size of browsers Kyphosus spp. and scrapers Scarus spp. increased $\sim$ twofold. This contributed to the formation of a second mode along the body size axis in the post-heatwave period, whereby a high proportion of the mass of the assemblage was concentrated both on small-bodied $(75 \% \mathrm{HDI}=1.5-26.8 \mathrm{~cm})$ and largebodied individuals (75\% HDI $=49.7-60.1 \mathrm{~cm}$; Table S4b).

\subsection{Shifts in taxonomic and functional structure}

Taxonomic and functional dissimilarities of the herbivorous fish assemblage were higher following the $2011 \mathrm{MHW}$ and remained

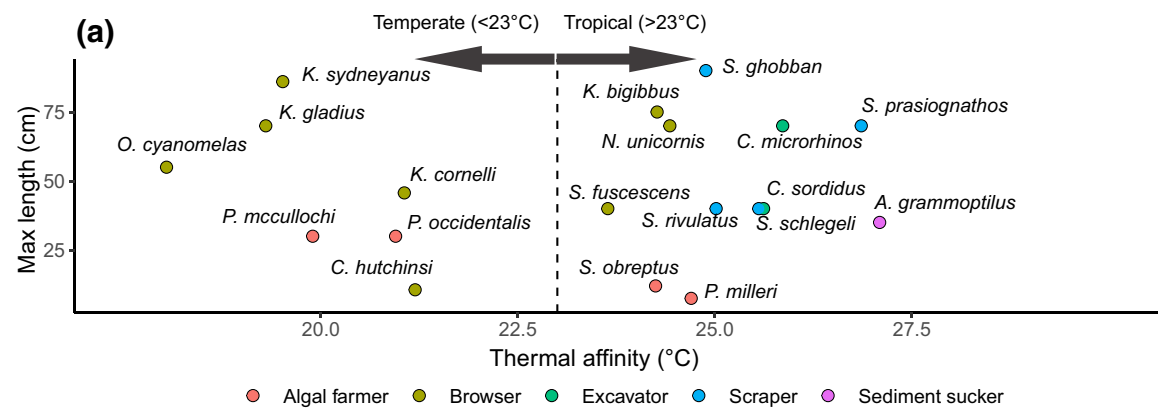

(b) Pre-heatwave

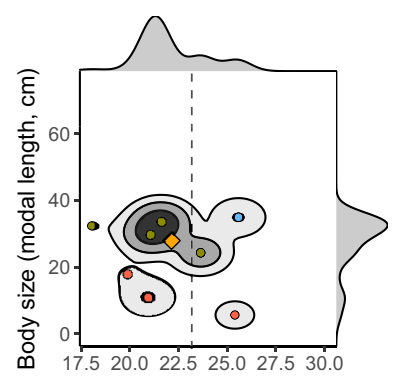

(c) Post-heatwave

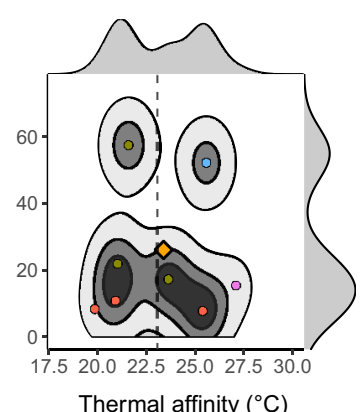

(d) Post-cooling

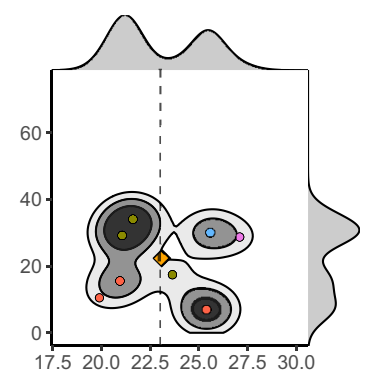

FIGURE 2 (a) Two-dimensional trait space showing the position of each of the 20 herbivorous fishes (pooled through years) recorded in the stereo diver operated vehicle (stereo-DOV) surveys and herbivory video assays, along axes of thermal affinity $\left({ }^{\circ} \mathrm{C}\right.$ ) and body size (maximum length obtained from Fishbase, $\mathrm{cm}$ ). (b-d) Changes in the density of fish individuals in the trait space across axes of thermal affinity $\left({ }^{\circ} \mathrm{C}\right.$ ) and body size (modal length from underwater surveys, $\mathrm{cm}$ ). Orange diamonds depict the community centroid (i.e. abundanceweighted mean trait values). Contours depict the 50\% (dark), 75\% (grey), and 95\% (light grey) highest density intervals (HDIs) of the distribution. Marginal distributions for thermal affinity $\left({ }^{\circ} \mathrm{C}\right)$ and body size (modal length, $\mathrm{cm}$ ) are provided in each panel. Species are coloured based on their phenotype-based functional group (i.e. 'how' function) 
comparatively dissimilar to pre-heatwave assemblages following periods of recent cooling (Figure 3). However, the relatively low values of Sørensen dissimilarities ( 0.2) when only considering compositional changes (i.e. presence-absence, ' $q$ ' $=0$ ) indicated that core herbivore species and functional entities were already present in the system prior to the 2011 MHW. Taxonomic and functional dissimilarities consistently increased when increasing the sensitivity of the metrics to relative abundances (i.e. ' $q$ ' > 0; Figure 3), indicating that changes in the abundance structure (i.e. increased evenness among temperate and tropical guilds, Figure $2 \mathrm{c}, \mathrm{d}$ ) were more important than compositional changes. Temporal dissimilarities, however, varied across sites, resulting in overall non-significant changes (Table S5), potentially stressing the importance of site-specific factors in determining the extent of species and functional changes in temperate regions undergoing tropicalization.

\section{3 | Changes in herbivory-related functions}

The abundance of species contributing to each herbivory-related function markedly differed through time periods (Figure 4), with the magnitude and significance of these changes differing between temperate and tropical guilds ('time period $\times$ thermal guild', $p<.001$, Table S6a). Tropical species responded more strongly to heatwave and cooling events, increasing after the $\mathrm{MHW}$ by $700 \%, 3190 \%$ and $1072 \%$ for macroalgae, turf, and sediment removers, respectively; and, declining by $93 \%, 20 \%$, and $63 \%$ in the cooling period, respectively. For tropical species, functional groups that rely most on filamentous algae, detritus, and cyanobacteria within the turf showed the steepest increase in abundance after the $2011 \mathrm{MHW}$, and the smallest declines following cooling periods (i.e. turf and sediment removers; Figure 4b,c). In contrast, the abundance of temperate macroalgal browsers remained relatively stable through time periods (Figure $4 a, p>.05$, Tukey pairwise comparisons). Interestingly, the abundance of temperate turf removers also increased after the $2011 \mathrm{MHW}$, although their net increase was 8 times smaller compared to their tropical counterpart, with no significant changes in abundance in the cooling period (Figure 2b). The identity (i.e. 'how' function) of species also shifted markedly (Figure 4d), from total abundances being strongly dominated by temperate browsers, to abundance becoming progressively more even, and algal farmers substantially increasing their relative contribution over time.

In the period between post-heatwave and subsequent cooling, herbivore abundance trends (Figure $4 a-c$ ) were paralleled by declines in the rates of herbivory-related functions (Figure $4 \mathrm{e}-\mathrm{g}, \mathrm{i}$ ). Mass standardized bite rates in the turf strongly declined following cooling periods, but the magnitude and significance of these changes varied between temperate and tropical guilds (Table S6b). Rates of macroalgae, turf, and sediment removal by tropical species declined by $96 \%, 99 \%$, and $99 \%$, respectively (Figure $4 \mathrm{e}-\mathrm{g}$ ). In contrast, temperate guilds showed no deviation from random expectation ( $p>.05$, Tukey pairwise comparisons). However, the functional identity of species contributing to turf bite rates displayed limited changes between post-heatwave and post-cooling periods, being dominated by scrapers and browsers of tropical affinity (Figure 4h; Figure S2a,b)

Mass standardized bite rates in the kelp transplants also declined strongly following cooling periods ('time period', $p<.001$, Table S6c), but these declines were of similar magnitudes ( 99\%) for both temperate and tropical macroalgae removers (Figure $4 \mathrm{i}$ ). Rates of macroalgal removal by tropical browsers (the chub Kyphosus bigibbus) were, on average, higher than that of their temperate counterparts (Kyphosus sydneyanus and Kyphosus gladius) at both time periods, but the bites in the former were substantially more variable, resulting in non-significant differences between thermal guilds irrespective of the time period (Table S6c). Yet, the tropical chub strongly dominated the total number of bites observed in the kelp transplants (Figure 4j; Figure S2c,d). Likewise, we found higher consumption rates on transplanted kelp individuals in the post-heatwave period (Figure 5), irrespective of the life-history stage ('time period $\times$ hour', $p<.001$, Table S7). Individual biomass remaining declined on average by $87 \%$ and $46 \%$ during the first $24 \mathrm{~h}$ in the post-heatwave period for adult and juvenile stages, respectively; while it declined by $57 \%$ and $41 \%$, respectively, in the post-cooling period. After $48 \mathrm{~h}$, almost complete kelp loss was observed in the post-heatwave period (99\% and $80 \%$ declined in adult and juvenile stages, respectively), while no complete kelp loss was observed in the post-cooling period ( $80 \%$ and $64 \%$ declined for adult and juvenile stages, respectively).

\section{4 | Trends in habitat structure}

Trends in consumption rates were paralleled by clear changes in benthic habitat structure. Following the $2011 \mathrm{MHW}$, and the documented regime shift from kelp to turf dominance, the cover of kelp at seascape levels - showed no signs of recovery (Figure 6). In contrast, the cover of Sargassum spp. increased progressively over time, attaining similar percent cover to the pre-heatwave period $(2006=35 \pm 4.8$, mean \pm SE \% cover; $2019=28.1 \pm 4.4$, mean \pm SE $\%$ cover). Yet, the system has remained dominated by turf algae, which on average accounts for $>50 \%$ of the benthic biogenic habitat structure (Figure 6).

\section{DISCUSSION}

Our study demonstrated that extreme MHWs can have legacy effects on the structure and functioning of ecological communities. Our hypothesis of shifts in the functional structure of the herbivorous fishes following the 2011 MHW was supported, with a clear shift from the dominance of cool-water browsing species to warmaffinity species that perform different herbivory roles (i.e. scraping, cropping, sediment sucking). However, this shift in dominance was not a result of the replacement of temperate with tropical species (Nakamura et al., 2013); most temperate species persisted following the MHW, and their abundances remained relatively stable. Thus, 
FIGURE 3 Heatmaps of (a) taxonomic and (b) functional dissimilarities of herbivorous fish assemblages through the three time periods, under increasing sensitivity to species' and functional entities' relative abundances: ' $q$ ' $=0$ (species composition only), ' $q$ ' = 1 (higher weight on common species), and ' $q$ ' $=2$ (higher weight on dominant species). Colour ramp indicates the magnitude of Sørensen pairwise dissimilarities (a) TD

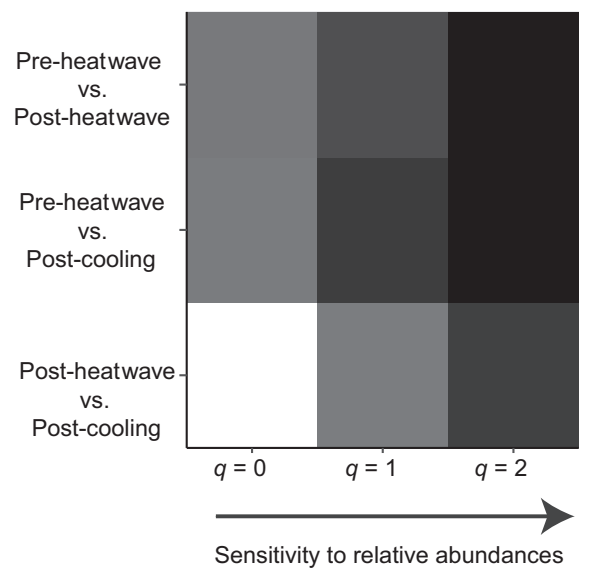

(b) FD

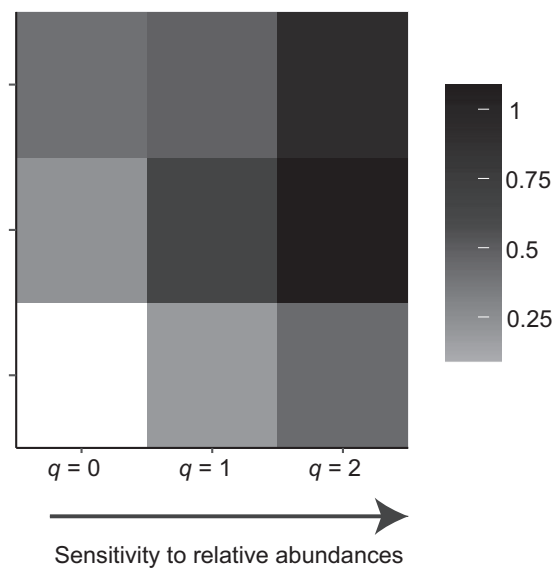

the shift in functional structure was largely the result of additional herbivory roles (scrapers, croppers, algal farmers, and detritus suckers) and increased evenness in the distribution of abundance across temperate and tropical guilds. Subsequent declines in the abundance of tropical species as conditions cooled and following winter cold spells did not appear to substantially impact the new functional structure, leading to what appears to have remained a novel assemblage with altered herbivory-related functions.

The increased evenness in the distribution of abundance in the trait space has important implications for community dynamics and ecosystem functioning. First, it suggests that cool- and warmaffinity species that are functionally similar can coexist in tropicalized temperate reefs, at least over the decadal scale investigated here, confirming the findings from other temperate-tropical transition zones (Smith et al., 2021; Zarco-Perello et al., 2020). This phenomenon might be facilitated by the following non-mutually exclusive processes: (i) reduced competition under background en vironmental variability (Roxburgh et al., 2004), (ii) high functional complementarity in feeding modes, behaviour, and habitat utilization among herbivorous fishes (Streit et al., 2019), and (iii) high diversity and/ or increased productivity of algal assemblages in temperate-tropical transition zones, which enhance specialization and reduce competition for resources (Burkepile \& Hay, 2011; Smith et al., 2021; Wernberg et al., 2011). Second, it suggests that increasing evenness among functional groups of herbivores might further enhance the overall herbivory process via complementarity effects in biodiversity-ecosystem functioning relationships (Lefcheck et al., 2019), a property that is key in tropical reefs to prevent shifts from coral to macroalgal dominance (Burkepile \& Hay, 2008; Rasher et al., 2013).

Many temperate ecosystems are experiencing a progressive increase in the number of tropical species and their abundances (Vergés, Steinberg, et al., 2014). Although we found that taxonomic and functional dissimilarities were partly driven by the addition of species and novel functional groups (e.g. the detritus sucker Acanthurus grammoptilus), values of total dissimilarity were low when considering only compositional changes, and consistently increased when accounting for changes in abundance structure. This indicates that core herbivore species and functional groups were already present in the system prior to the $2011 \mathrm{MHW}$, highlighting important nonlinearities in the tropicalization process in nearshore ecosystems along the western Australian coastline. It is likely that tropicalization of these systems is enhanced by the cumulative effects of MHWs (Zinke et al., 2014), whereby the rapid arrival of tropical propagules and subsequent demographic explosion during warm periods (Smith et al., 2019) might be followed by mechanisms that facilitate their short-term persistence during cooling phases of the ENSO (Zarco-Perello et al., 2019).

In this context, it must be noted that the lack of temporal replication within each period (i.e. pre-heatwave, post-heatwave, and postcooling) is an important statistical limitation of the current study. Large variability between years within periods could confound the observed differences in the fish trait structure and herbivory rates reported here. In a supplementary analysis, we showed that this interannual variability for the post-cooling period was low (Figure S3), a result that could be explained by the relatively low variability in oceanographic conditions within periods relative to that found between periods (Figure 1b,c). Previous studies have also found that fish assemblage structure in the region closely tracked these marked changes in oceanography (Day et al., 2018; Feng et al., 2021; Wernberg et al., 2013), driven by changes in ENSO phases (warming phases during 'La Niña' events vs. cooling phases during 'El Niño' events), that modulates the strength and advection of the Leeuwin current (Feng et al., 2008). Hence, we make the assumption that interannual variability within the pre-heatwave and post-heatwave period was lower that the differences found between periods, and thus the fish trait structure reported here is a reliable characterization of the community state in those periods.

Multiple mechanisms can enhance the persistence of tropical species during unfavourable, cool, environmental periods. Previous studies in the region, for instance, have found that sheltered embayments can enhance the local recruitment success of some of these tropical species (Zarco-Perello et al., 2021). Changes in the biotic environment associated with a regime-shift, from canopy-forming macroalgae to turf dominance, might also facilitate their demographic explosion and subsequent short-term persistence. This aligns with 
Macroalgal removal

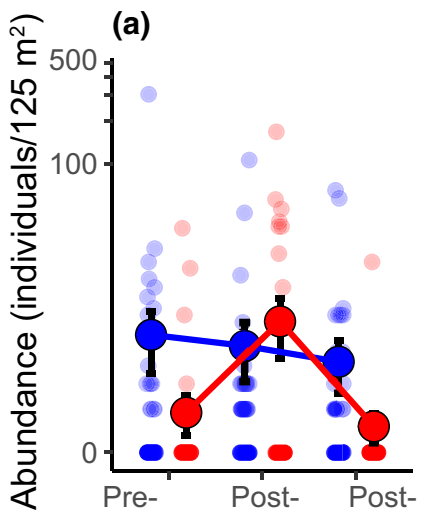

heatwave heatwave cooling

(e)

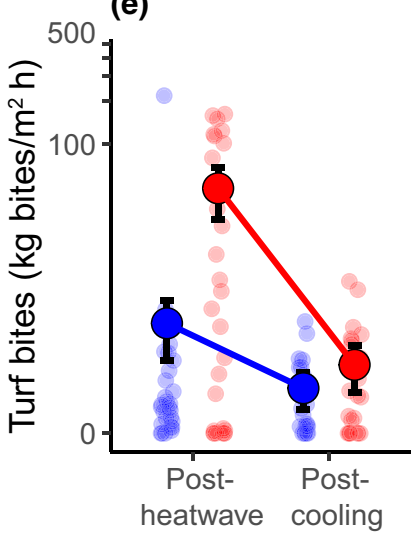

(i)

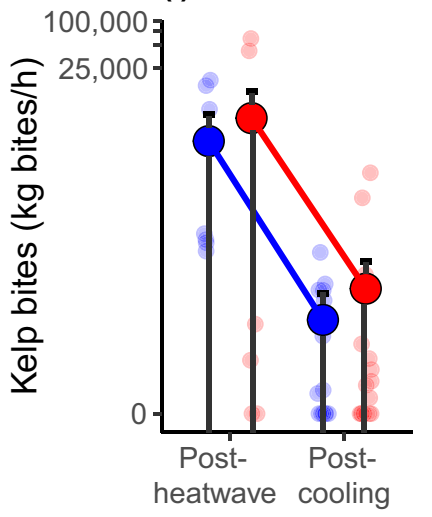

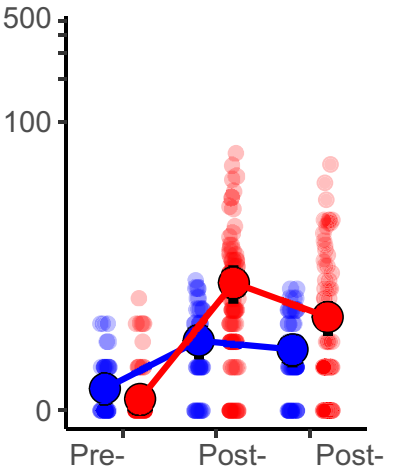

heatwave heatwave cooling

(f)

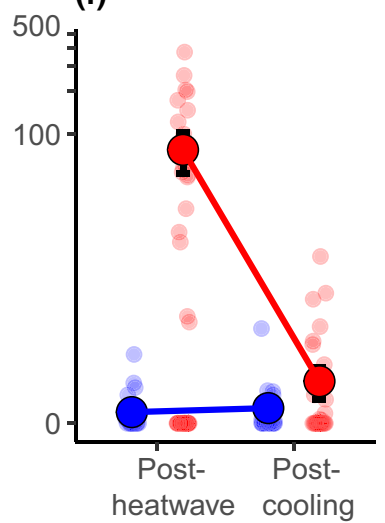

Sediment removal

(c)

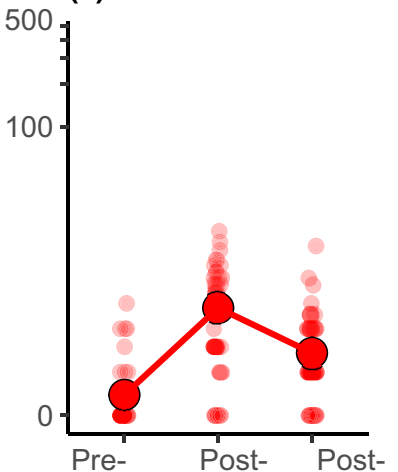

heatwave heatwave cooling
'How'

(d)

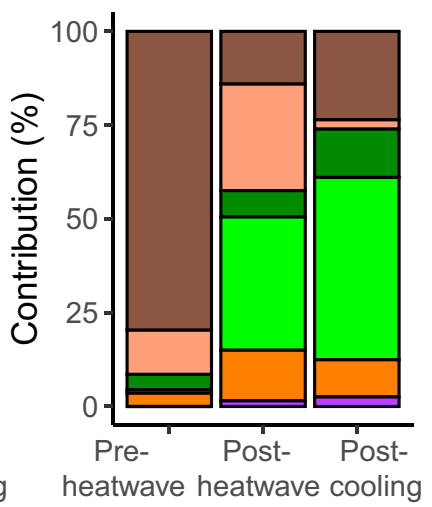

(h)

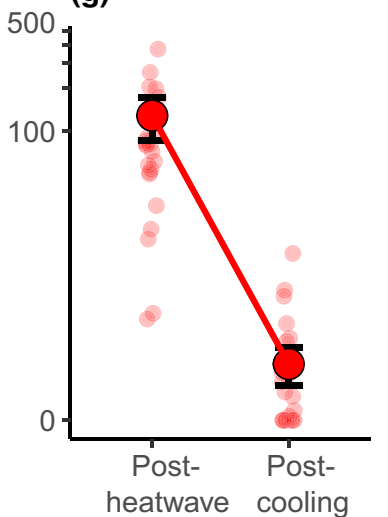

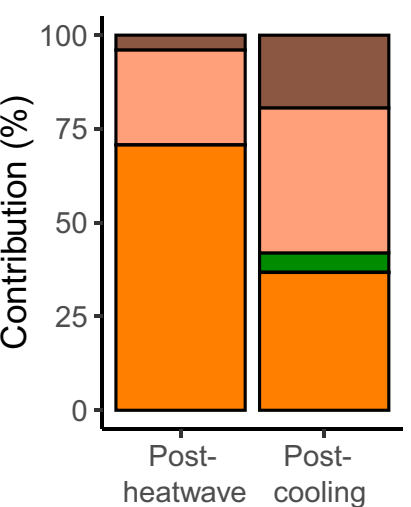

(j)

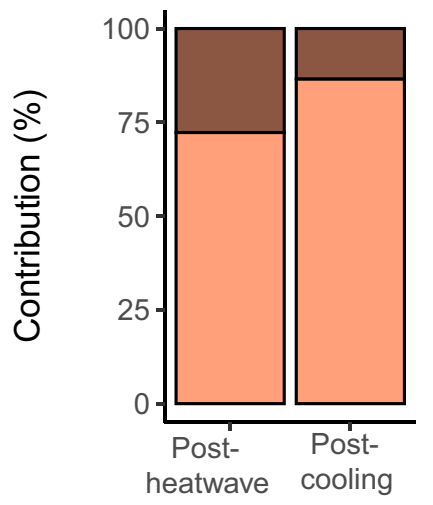

FIGURE 4 Mean $( \pm$ SE) (a-c) abundances, $(e-g)$ turf bite rates, and (i) kelp bite rates of species (pooled) contributing to macroalgae, turf, and sediment removal through time periods, as a function of their thermal guild (temperate = blue dots; tropical = red dots). Larger dots are generalized linear mixed models (GLMMs) average model estimates, and jittered points are transect-level values. For visualization purposes, the $y$-axis is shown in log-scale. (d, h, j) Proportional contribution (\%) of each herbivore guild (i.e. 'how' function: browser, algal farmer, scraper, and detritus sucker) to (d) total abundances, (h) total turf bite rates, (i) total kelp bite rates for each time period. Colours denote herbivore guilds, and colour intensity indicates species thermal guild (dark = temperate; light $=$ tropical)

our finding that fish species that rely most on filamentous algae, detritus, and cyanobacteria within the turf, displayed the steepest abundance increases following the $2011 \mathrm{MHW}$, while their abundance decline following cooling periods was comparatively smaller to other tropical species. Even temperate algal farmers, for which temperatures during the MHW exceeded those typically experienced by these species during seasonal extremes at the warmest edge of their range (i.e. summer maximum annual temperatures; Stuart-Smith et al., 2017), increased during the 2011 MHW. This may have been driven by smaller-scale thermal refuges or short-term physiological acclimation (Morley et al., 2019), for example, and supported by an increased availability of farming areas (Saunders et al., 2015). 
FIGURE 5 Mean $( \pm$ SE) (a) adult and (b) juvenile kelp biomass $(\mathrm{g})$ remaining through a $48 \mathrm{~h}$ period in the postheatwave (orange) and post-cooling (purple) periods. Larger dots are generalized linear mixed models (GLMMs) average estimates, and jittered dots are transect-level values (a) Adult

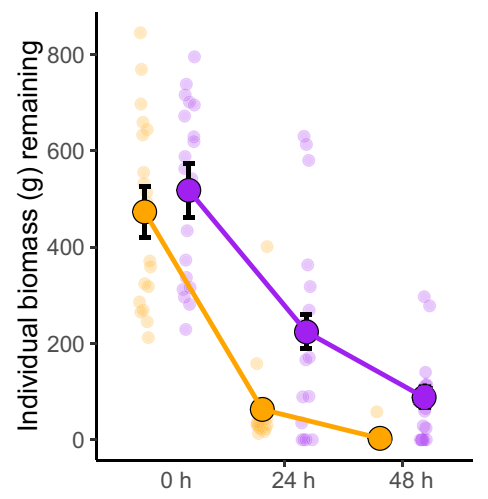

(b) Juvenile

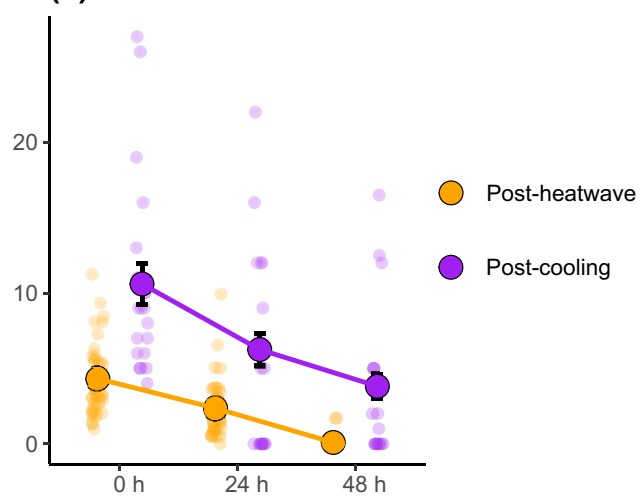

FIGURE 6 Temporal trends in the percent cover (mean $\pm \mathrm{SE}$ ) of benthic morpho-functional algae groups: turf (red dots), Sargassum spp. (green dots), and the kelp Ecklonia radiata (blue dots). Jittered points are transect-level values for each response metric

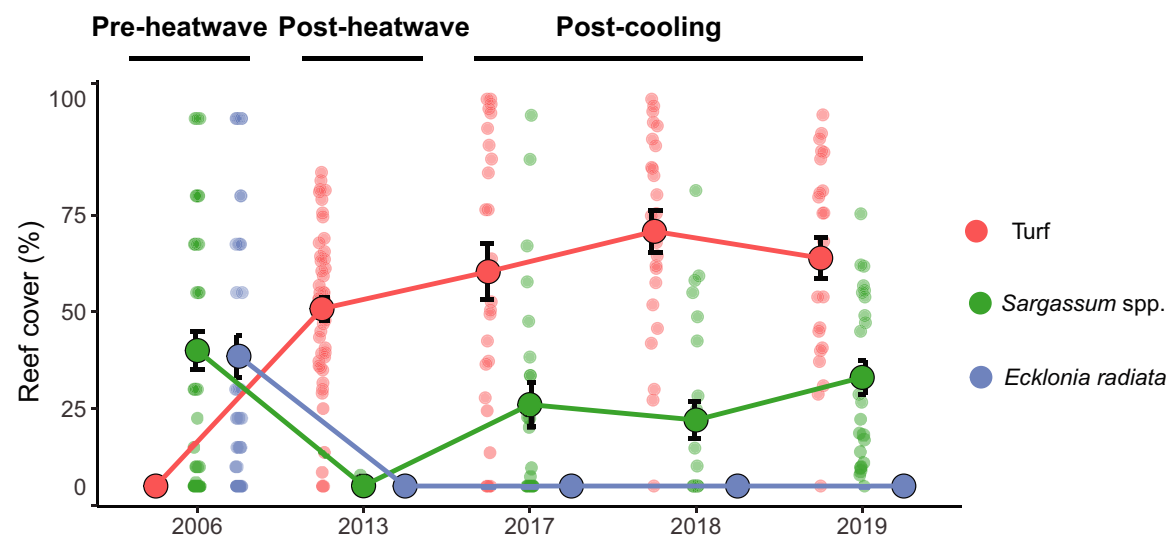

A key remaining question is the extent to which this altered functional trait structure of herbivorous fishes might contribute to the recovery dynamics of macroalgal foundation species. High browsing and grazing intensity by herbivorous fishes can suppress macroalgal recovery in the study region, maintaining an alternate ecosystem state dominated by turf algae (Bennett et al., 2015). Replicating these experiments 10 years after the $2011 \mathrm{MHW}$, we found that while the intensity of herbivory-related functions (macroalgal, turf, and sediment removal) occurred alongside the declines in the abundances of tropical fishes following a period of cooling, the trait composition of species contributing to these functions remained relatively unaltered. Browsing rates in kelp transplants were dominated by the tropical drummer Kyphosus bigibbus, a species that can rapidly consume kelp individuals during feeding frenzies (some transplants consumed in $<5$ min by schools of this species). Hence, although rates of kelp removal declined and kelp transplants were consumed less rapidly in the post-cooling period, the persistence of tropical drummers might still prohibit kelp canopy recovery at seascape scales (Zarco-Perello et al., 2021). Likewise, even though grazing intensity declined in the post-cooling period, this function was almost exclusively driven by tropical species, the black rabbitfish Siganus fuscescens and the scraping parrotfishes Scarus spp. Rabbitfishes are among the most important consumers of Sargassum spp. on coral reefs (Bennett \& Bellwood, 2011; Fox \& Bellwood, 2008), and play an increasingly important role in the consumption of seaweed recruits in warming temperate seas (Vergés, Steinberg, et al., 2014; Vergés, Tomas, et al., 2014). Through their scraping feeding mode, parrotfishes can remove large volumes of the reef matrix that can contain macroalgal recruits (Hoey \& Bonaldo, 2018). The relative impact of parrotfishes on the benthos might have also been enhanced as a result of a twofold increase in their population modal size during the heatwave (Shantz et al., 2020), a demographic response that has also been documented as a result of coral bleaching and the proliferation of turf algae on coral reefs (Taylor et al., 2020).

The evidence gathered here suggests that the persistence of an altered trait structure of herbivorous fish assemblages can shape the recovery dynamics of macroalgal foundation species in tropicalized temperate reefs, fundamentally shifting the nature of herbivorealgae interactions. However, other bottom-up, feedback, mechanisms could also have contributed to the observed persistence of turf and Sargassum spp. in the region formerly dominated by kelp forests. Kelp propagule supply may have been reduced following their local decline (i.e. meso-scale connectivity, S. Bell unpublished), which can be further exacerbated by the limited large-scale connectivity with populations at higher (i.e. more temperate) latitudes (Coleman et al., 2011; Wernberg et al., 2018). In contrast, Sargassum spp. is characterized by greater dispersal potential (Kendrick \& Walker, 1994), partly facilitated by rafting strategies (Zubia et al., 2015), and the potential of propagules to arrive from both tropical and temperate latitudes. Furthermore, high sediment concentrations bounded within algal turfs can suppress the recovery of kelp forests (Gorman \& Connell, 2009), while Sargassum spp. have a superior ability than kelps to recruit into sediment laden turfs (Bennett \& Wernberg, 2014), and is usually more warm tolerant and resistant 
to herbivore pressure (Loffler et al., 2018). These differential mechanisms can thus promote the recovery of Sargassum spp. over kelp, although further experimental manipulations would be useful to decouple the relative importance of top-down (i.e. herbivory by fishes) and bottom-up (i.e. connectivity and recruitment) mechanisms in the recovery dynamics of tropicalized temperate reefs.

Trait-based approaches provide a promising tool to advance our understanding of anthropogenic impacts on ecosystem functioning and resilience (Mcgill et al., 2006). We demonstrated how changes in the functional trait structure of an herbivorous fish assemblage fundamentally shifted the nature of herbivory-related functions following an extreme disturbance event, with lasting consequences in the recovery dynamics of canopy-forming macroalgal foundation species. A critical question remains in identifying the temporal timescales over which tropical herbivorous fishes can persist through cooler periods before future MHW occur (Oliver et al., 2019). Given the broad applicability of species traits across geographically disparate regions, our results exemplified the value of monitoring changes in the functional trait structure of consumers to predict and adapt to the future configuration of changing reef ecosystems.

\section{ACKNOWLEDGEMENTS}

We thank Heather Denham, Mason Sullivan, Jan Ranson, and other members of the Wernberg laboratory for fieldwork assistance. N.E.B acknowledges support from the Australian Government International Research Training Program, the Holsworth Wildlife Research Endowment (Ecological society of Australia, RA/1/411/101), the Sea World Research \& Rescue Foundation (SWR/14/2019), and the Robson \& Robertson UWA PhD awards. T.W. received support from the Hermon Slade Foundation (HSF13/13) and the Australian Research Council (DP170100023, DP190100058).

\section{CONFLICT OF INTEREST}

The authors declare no conflict of interest.

\section{DATA AVAILABILITY STATEMENT}

The data and $\mathrm{R}$ code supporting thes findings of this study are openly available in the author personal GitHub repository (https:// github.com/NestorBosch/Herbivory_Trait_Structure). Please cite Bosch (2021). NestorBosch/Herbivory_Trait_Structure (v.1). Zenodo (https://doi.org/10.5281/zenodo.5804320) if using these materials.

\section{ORCID}

Nestor E. Bosch (D) https://orcid.org/0000-0003-0421-8456 Matthew McLean (D) https://orcid.org/0000-0001-6518-6043 Salvador Zarco-Perello (D) https://orcid.org/0000-0001-9435-8545 Scott Bennett (D) https://orcid.org/0000-0003-2969-7430 Rick D. Stuart-Smith (D) https://orcid.org/0000-0002-8874-0083 Adriana Vergés (D) https://orcid.org/0000-0002-3507-1234 Albert Pessarrodona (D) https://orcid.org/0000-0002-6057-9937 Fernando Tuya (D) https://orcid.org/0000-0001-8316-5887 Tim Langlois (D) https://orcid.org/0000-0001-6404-4000 Sahira Bell (D) https://orcid.org/0000-0001-9237-7507
Benjamin J. Saunders (D) https://orcid.org/0000-0003-1929-518X Thomas Wernberg (D) https://orcid.org/0000-0003-1185-9745

\section{REFERENCES}

Albouy, C., Velez, L., Coll, M., Colloca, F., Le Loc'h, F., Mouillot, D., \& Gravel, D. (2014). From projected species distribution to food-web structure under climate change. Global Change Biology, 20(3), 730741. https://doi.org/10.1111/gcb.12467

Bates, A. E., Pecl, G. T., Frusher, S., Hobday, A. J., Wernberg, T., Smale, D. A., Sunday, J. M., Hill, N. A., Dulvy, N. K., Colwell, R. K., Holbrook, N. J., Fulton, E. A., Slawinski, D., Feng, M., Edgar, G. J., Radford, B. T., Thompson, P. A., \& Watson, R. A. (2014). Defining and observing stages of climate-mediated range shifts in marine systems. Global Environmental Change: Human and Policy Dimensions, 26(1), 27-38. https://doi.org/10.1016/j.gloenvcha.2014.03.009

Bellwood, D. R., Streit, R. P., Brandl, S. J., \& Tebbett, S. B. (2018). The meaning of the term "function" in ecology: A coral reef perspective. Functional Ecology, 33(6), 948-961. https://doi. org/10.1111/1365-2435.13265

Bennett, S., \& Bellwood, D. R. (2011). Latitudinal variation in macroalgal consumption by fishes on the Great Barrier Reef. Marine Ecology Progress Series, 426, 241-252. https://doi.org/10.3354/meps09016

Bennett, S., \& Wernberg, T. (2014). Canopy facilitates seaweed recruitment on subtidal temperate reefs. The Journal of Ecology, 102(6), 1462-1470. https://doi.org/10.1111/1365-2745.12302

Bennett, S., Wernberg, T., Harvey, E. S., Santana-Garcon, J., \& Saunders, B. J. (2015). Tropical herbivores provide resilience to a climatemediated phase shift on temperate reefs. Ecology Letters, 18(7), 714-723. https://doi.org/10.1111/ele.12450

Blois, J. L., Zarnetske, P. L., Fitzpatrick, M. C., \& Finnegan, S. (2013). Climate change and the past, present, and future of biotic interactions. Science, 341(6145), 499-504. https://doi.org/10.1126/scien ce.1237184

Blowes, S. A., Supp, S. R., Antão, L. H., Bates, A., Bruelheide, H., Chase, J. M., Moyes, F., Magurran, A., McGill, B., Myers-Smith, I. H., Winter, M., Bjorkman, A. D., Bowler, D. E., Byrnes, J. E. K., Gonzalez, A., Hines, J., Isbell, F., Jones, H. P., Navarro, L. M., ... Dornelas, M. (2019). The geography of biodiversity change in marine and terrestrial assemblages. Science, 366(6463), 339-345. https://doi. org/10.1126/science.aaw1620

Bonebrake, T. C., Brown, C. J., Bell, J. D., Blanchard, J. L., Chauvenet, A., Champion, C., Chen, I.-C., Clark, T. D., Colwell, R. K., Danielsen, F., Dell, A. I., Donelson, J. M., Evengård, B., Ferrier, S., Frusher, S., Garcia, R. A., Griffis, R. B., Hobday, A. J., Jarzyna, M. A., ... Pecl, G. T. (2018). Managing consequences of climate-driven species redistribution requires integration of ecology, conservation and social science. Biological Reviews of the Cambridge Philosophical Society, 93(1), 284-305. https://doi.org/10.1111/brv.12344

Bosch, N. E. (2021). NestorBosch/Herbivory_Trait_Structure (v.1). Zenodo. https://doi.org/10.5281/zenodo.5804320

Bosch, N. E., Gonçalves, J. M., Erzini, K., \& Tuya, F. (2017). "How" and "what" matters: Sampling method affects biodiversity estimates of reef fishes. Ecology and Evolution, 7(13), 4891-4906. https://doi. org/10.1002/ece3.2979

Brandl, S. J., Rasher, D. B., Côté, I. M., Casey, J. M., Darling, E. S., Lefcheck, J. S., \& Duffy, J. E. (2019). Coral reef ecosystem functioning: Eight core processes and the role of biodiversity. Frontiers in Ecology and the Environment, 17(8), 445-454. https://doi.org/10.1002/ fee. 2088

Brooks, M. E., Kristensen, K., Benthem, K. J., Magnusson, A., Berg, C. W., Nielsen, A., Skaug, H. J., Mächler, M., \& Bolker, B. M. (2017). gImmTMB balances speed and flexibility among packages for zeroinflated generalized linear mixed modeling. The $R$ Journal, 9(2), 378. https://doi.org/10.32614/rj-2017-066 
Burkepile, D. E., \& Hay, M. E. (2008). Herbivore species richness and feeding complementarity affect community structure and function on a coral reef. Proceedings of the National Academy of Sciences of the United States of America, 105(42), 16201-16206. https://doi. org/10.1073/pnas.0801946105

Burkepile, D. E., \& Hay, M. E. (2011). Feeding complementarity versus redundancy among herbivorous fishes on a Caribbean reef. Coral Reefs, 30(2), 351-362. https://doi.org/10.1007/s0033 8-011-0726-6

Burrows, M. T., Bates, A. E., Costello, M. J., Edwards, M., Edgar, G. J., Fox, C. J., Halpern, B. S., Hiddink, J. G., Pinsky, M. L., Batt, R. D., Molinos, J. G., Payne, B. L., Schoeman, D. S., Stuart-Smith, R. D., \& Poloczanska, E. S. (2019). Ocean community warming responses explained by thermal affinities and temperature gradients. Nature Climate Change, 9(12), 959-963. https://doi.org/10.1038/s4155 8-019-0631-5

Burrows, M. T., Schoeman, D. S., Buckley, L. B., Moore, P., Poloczanska, E. S., Brander, K. M., Brown, C., Bruno, J. F., Duarte, C. M., Halpern, B. S., Holding, J., Kappel, C. V., Kiessling, W., O'Connor, M. I., Pandolfi, J. M., Parmesan, C., Schwing, F. B., Sydeman, W. J., \& Richardson, A. J. (2011). The pace of shifting climate in marine and terrestrial ecosystems. Science, 334(6056), 652-655. https://doi.org/10.1126/ science.1210288

Cadotte, M. W., Albert, C. H., \& Walker, S. C. (2013). The ecology of differences: Integrating evolutionary and functional distances. Ecology Letters, 16, 1234-1244. https://doi.org/10.1111/ ele.12161

Chao, A., Chiu, C.-H., \& Jost, L. (2014). Unifying species diversity, phylogenetic diversity, functional diversity, and related similarity and differentiation measures through hill numbers. Annual Review of Ecology, Evolution, and Systematics, 45(1), 297-324. https://doi. org/10.1146/annurev-ecolsys-120213-091540

Chao, A., Chiu, C., Villéger, S., Sun, I., Thorn, S., Lin, Y., Chiang, J., \& Sherwin, W. B. (2019). An attribute-diversity approach to functional diversity, functional beta diversity, and related (dis)similarity measures. Ecological Monographs, 89(2), e01343. https://doi. org/10.1002/ecm.1343

Coleman, M. A., Roughan, M., Macdonald, H. S., Connell, S. D., Gillanders, B. M., Kelaher, B. P., \& Steinberg, P. D. (2011). Variation in the strength of continental boundary currents determines continentwide connectivity in kelp. Journal of Ecology, 99(4), 1026-1032. https://doi.org/10.1111/j.1365-2745.2011.01822.x

Connell, S. D., Foster, M. S., \& Airoldi, L. (2014). What are algal turfs? Towards a better description of turfs. Marine Ecology Progress Series, 495, 299-307. https://doi.org/10.3354/meps10513

Day, P. B., Stuart-Smith, R. D., Edgar, G. J., \& Bates, A. E. (2018). Species' thermal ranges predict changes in reef fish community structure during 8 years of extreme temperature variation. Diversity and Distributions, 24(8), 1036-1046. https://doi.org/10.1111/ ddi.12753

Dornelas, M., Gotelli, N. J., McGill, B., Shimadzu, H., Moyes, F., Sievers, C., \& Magurran, A. E. (2014). Assemblage time series reveal biodiversity change but not systematic loss. Science, 344(6181), 296299. https://doi.org/10.1126/science.1248484

Duffy, J. E., \& Emmett Duffy, J. (2009). Why biodiversity is important to the functioning of real-world ecosystems. Frontiers in Ecology and the Environment, 7(8), 437-444. https://doi.org/10.1890/070195

Feng, M., Biastoch, A., Böning, C., Caputi, N., \& Meyers, G. (2008). Seasonal and interannual variations of upper ocean heat balance off the west coast of Australia. Journal of Geophysical Research, 113(C12). https://doi.org/10.1029/2008jc004908

Feng, M., Caputi, N., Chandrapavan, A., Chen, M., Hart, A., \& Kangas, M. (2021). Multi-year marine cold-spells off the west coast of Australia and effects on fisheries. Journal of Marine Systems, 214. https://doi. org/10.1016/j.jmarsys.2020.103473
Fortunel, C., Valencia, R., Wright, S. J., Garwood, N. C., \& Kraft, N. J. B. (2016). Functional trait differences influence neighbourhood interactions in a hyperdiverse Amazonian forest. Ecology Letters, 19(9), 1062-1070. https://doi.org/10.1111/ele.12642

Fox, R. J., \& Bellwood, D. R. (2008). Remote video bioassays reveal the potential feeding impact of the rabbitfish Siganus canaliculatus (f: Siganidae) on an inner-shelf reef of the Great Barrier Reef. Coral Reefs, 27(3), 605-615. https://doi.org/10.1007/s0033 8-008-0359-6

Fox, R. J., Sunderland, T. L., Hoey, A. S., \& Bellwood, D. R. (2009). Estimating ecosystem function: Contrasting roles of closely related herbivorous rabbitfishes (Siganidae) on coral reefs. Marine Ecology Progress Series, 385, 261-269. https://doi.org/10.3354/meps08059

Froese, R., \& Pauly, D. (2012). Fishbase (www database). World Wide Web Electronic Publications. Retrieved from http://www. Fishbase.Org

Gagic, V., Bartomeus, I., Jonsson, T., Taylor, A., Winqvist, C., Fischer, C., Slade, E. M., Steffan-Dewenter, I., Emmerson, M., Potts, S. G., Tscharntke, T., Weisser, W., \& Bommarco, R. (2015). Functional identity and diversity of animals predict ecosystem functioning better than species-based indices. Proceedings of the Royal Society B: Biological Sciences, 282(1801), 20142620. https://doi.org/10.1098/ rspb.2014.2620

García Molinos, J., Halpern, B. S., Schoeman, D. S., Brown, C. J., Kiessling, W., Moore, P. J., Pandolfi, J. M., Poloczanska, E. S., Richardson, A. J., \& Burrows, M. T. (2016). Climate velocity and the future global redistribution of marine biodiversity. Nature Climate Change, 6(1), 83-88. https://doi.org/10.1038/nclimate2769

Gilman, S. E., Urban, M. C., Tewksbury, J., Gilchrist, G. W., \& Holt, R. D. (2010). A framework for community interactions under climate change. Trends in Ecology \& Evolution, 25(6), 325-331. https://doi. org/10.1016/j.tree.2010.03.002

Goetze, J. S., Bond, T., McLean, D. L., Saunders, B. J., Langlois, T. J., Lindfield, S., Fullwood, L. A. F., Driessen, D., Shedrawi, G., \& Harvey, E. S. (2019). A field and video analysis guide for diver operated stereo-video. Methods in Ecology and Evolution, 10(7), 1083-1090. https://doi.org/10.1111/2041-210X.13189

Gómez-Gras, D., Linares, C., Dornelas, M., Madin, J. S., Brambilla, V., Ledoux, J.-B., López-Sendino, P., Bensoussan, N., \& Garrabou, J. (2021). Climate change transforms the functional identity of Mediterranean coralligenous assemblages. Ecology Letters, 24(5), 1038-1051. https://doi.org/10.1111/ele.13718

Gorman, D., \& Connell, S. D. (2009). Recovering subtidal forests in human-dominated landscapes. The Journal of Applied Ecology, 46(6), 1258-1265. https://doi.org/10.1111/j.1365-2664.2009.01711.x

Hartig, F. (2021). DHARMa: Residual diagnostics for hierarchical (multilevel/mixed) regression models. $\mathrm{R}$ package version 0.4.1. Retrieved from https://CRAN.R-project.org/package=DHARMa

Hillebrand, H., Blasius, B., Borer, E. T., Chase, J. M., Downing, J. A., Eriksson, B. K., Filstrup, C. T., Harpole, W. S., Hodapp, D., Larsen, S., Lewandowska, A. M., Seabloom, E. W., Van de Waal, D. B., \& Ryabov, A. B. (2018). Biodiversity change is uncoupled from species richness trends: Consequences for conservation and monitoring. Journal of Applied Ecology, 55(1), 169-184. https://doi. org/10.1111/1365-2664.12959

Hoey, A. S., \& Bellwood, D. R. (2009). Limited functional redundancy in a high diversity system: Single species dominates key ecological process on coral reefs. Ecosystems, 12(8), 1316-1328. https://doi. org/10.1007/s10021-009-9291-z

Hoey, A. S., \& Bonaldo, R. M. (2018). Biology of parrotfishes. CRC Press.

Hughes, T. P., Graham, N. A. J., Jackson, J. B. C., Mumby, P. J., \& Steneck, R. S. (2010). Rising to the challenge of sustaining coral reef resilience. Trends in Ecology \& Evolution, 25(11). 633-642. https://doi. org/10.1016/j.tree.2010.07.011

Kendrick, G. A., \& Walker, D. I. (1994). Role of recruitment in structuring beds of Sargassum spp. (phaeophyta) at Rottnest Island, 
Western Australia. Journal of Phycology, 30(2), 200-208. https:// doi.org/10.1111/j.0022-3646.1994.00200.x

Laliberté, E., Legendre, P., \& Shipley, B. (2014). FD: Measuring functional diversity from multiple traits, and other tools for functional ecology. $\mathrm{R}$ package version 1.0-12.

Lefcheck, J. S., Edgar, G. J., Stuart-Smith, R. D., Bates, A. E., Waldock, C., Brandl, S. J., Kininmonth, S., Ling, S. D., Duffy, J. E., Rasher, D. B., \& Agrawal, A. F. (2021). Species richness and identity both determine the biomass of global reef fish communities. Nature Communications, 12(1), 1-9. https://doi.org/10.1038/s41467-02127212-9

Lefcheck, J. S., Innes-Gold, A. A., Brandl, S. J., Steneck, R. S., Torres, R. E., \& Rasher, D. B. (2019). Tropical fish diversity enhances coral reef functioning across multiple scales. Science Advances, 5(3), eaav6420. https://doi.org/10.1126/sciadv.aav6420

Lenoir, J., \& Svenning, J.-C. (2015). Climate-related range shifts - A global multidimensional synthesis and new research directions. Ecography, 38(1), 15-28. https://doi.org/10.1111/ecog.00967

Loffler, Z., Graba-Landry, A., Kidgell, J. T., McClure, E. C., Pratchett, M. S., \& Hoey, A. S. (2018). Holdfasts of Sargassum swartzii are resistant to herbivory and resilient to damage. Coral Reefs, 37(4), 1075-1084. https://doi.org/10.1007/s00338-018-01745-w

Longo, G. O., Ferreira, C. E. L., \& Floeter, S. R. (2014). Herbivory drives large-scale spatial variation in reef fish trophic interactions. Ecology and Evolution, 4(23), 4553-4566. https://doi.org/10.1002/ ece 3.1310

Luiz, O. J., Allen, A. P., Robertson, D. R., Floeter, S. R., Kulbicki, M., Vigliola, L., Becheler, R., \& Madin, J. S. (2013). Adult and larval traits as determinants of geographic range size among tropical reef fishes. Proceedings of the National Academy of Sciences of the United States of America, 110(41), 16498-16502. https://doi.org/10.1073/ pnas. 1304074110

Magneville, C., Loiseau, N., Albouy, C., Casajus, N., Claverie, T., Escalas, A., Leprieur, F., Maire, E., Mouillot, D., \& Villeger, S. (2021). mFD: An R package to compute and illustrate the multiple facets of functional diversity. Ecography. https://doi.org/10.1111/ ecog.05904

Magurran, A. E., Dornelas, M., Moyes, F., Gotelli, N. J., \& McGill, B. (2015). Rapid biotic homogenization of marine fish assemblages. Nature Communications, 6(1), 1-5. https://doi.org/10.1038/ncomms9405

Mcgill, B. J., Dornelas, M., Gotelli, N. J., \& Magurran, A. E. (2015). Fifteen forms of biodiversity trend in the Anthropocene. Trends in Ecology \& Evolution, 30(2), 104-113. https://doi.org/10.1016/j. tree.2014.11.006

Mcgill, B., Enquist, B., Weiher, E., \& Westoby, M. (2006). Rebuilding community ecology from functional traits. Trends in Ecology \& Evolution, 21(4), 178-185. https://doi.org/10.1016/j.tree.2006.02.002

McLean, M., Mouillot, D., Lindegren, M., Engelhard, G., Villéger, S., Marchal, P., Brind'Amour, A., \& Auber, A. (2018). A climatedriven functional inversion of connected marine ecosystems. Current Biology, 28(22), 3654-3660. https://doi.org/10.1016/j. cub.2018.09.050

McLean, M., Stuart-Smith, R. D., Villéger, S., Auber, A., Edgar, G. J., MacNeil, M. A., Loiseau, N., Leprieur, F., \& Mouillot, D. (2021). Trait similarity in reef fish faunas across the world's oceans. Proceedings of the National Academy of Sciences of the United States of America, 118(12). https://doi.org/10.1073/pnas.2012318118

Meredith, M., \& Kruschke, J. (2020). HDInterval: Highest (posterior) density intervals. R package version 0.2.2. Retrieved from https://CRAN.Rproject.org $/$ package $=$ HDInterval

Morley, S. A., Peck, L. S., Sunday, J. M., Heiser, S., \& Bates, A. E. (2019). Physiological acclimation and persistence of ectothermic species under extreme heat events. Global Ecology and Biogeography, 28(7), 1018-1037. https://doi.org/10.1111/geb.12911

Mouillot, D., Graham, N. A. J., Villéger, S., Mason, N. W. H., \& Bellwood, D. R. (2013). A functional approach reveals community responses to disturbances. Trends in Ecology \& Evolution, 28(3), 167-177. https://doi.org/10.1016/j.tree.2012.10.004

Mouillot, D., Villéger, S., Scherer-Lorenzen, M., \& Mason, N. W. H. (2011). Functional structure of biological communities predicts ecosystem multifunctionality. PLoS One, 6(3), e17476. https://doi.org/10.1371/ journal.pone.0017476

Nakamura, Y., Feary, D. A., Kanda, M., \& Yamaoka, K. (2013). Tropical fishes dominate temperate reef fish communities within western Japan. PLoS One, 8(12), e81107. https://doi.org/10.1371/journ al.pone.0081107

Oliver, E. C. J., Burrows, M. T., Donat, M. G., Sen Gupta, A., Alexander, L. V., Perkins-Kirkpatrick, S. E., Benthuysen, J. A., Hobday, A. J., Holbrook, N. J., Moore, P. J., Thomsen, M. S., Wernberg, T., \& Smale, D. A. (2019). Projected marine heatwaves in the 21st century and the potential for ecological impact. Frontiers in Marine Science, 6, 734. https://doi.org/10.3389/fmars.2019.00734

Oliver, E. C. J., Donat, M. G., Burrows, M. T., Moore, P. J., Smale, D. A., Alexander, L. V., Benthuysen, J. A., Feng, M., Sen Gupta, A., Hobday, A. J., Holbrook, N. J., Perkins-Kirkpatrick, S. E., Scannell, H. A., Straub, S. C., \& Wernberg, T. (2018). Longer and more frequent marine heatwaves over the past century. Nature Communications, 9(1), 1-12. https://doi.org/10.1038/s41467-018-03732-9

Parmesan, C., \& Yohe, G. (2003). A globally coherent fingerprint of climate change impacts across natural systems. Nature, 421(6918), 37-42. https://doi.org/10.1038/nature01286

Parravicini, V., Casey, J. M., Schiettekatte, N. M. D., Brandl, S. J., PozasSchacre, C., Carlot, J., Edgar, G. J., Graham, N. A. J., HarmelinVivien, M., Kulbicki, M., Strona, G., \& Stuart-Smith, R. D. (2020). Delineating reef fish trophic guilds with global gut content data synthesis and phylogeny. PLoS Biology, 18(12), e3000702. https:// doi.org/10.1371/journal.pbio.3000702

Pearce, A., Slawinski, D., Feng, M., Hutchins, B., \& Fearns, P. (2011). Modelling the potential transport of tropical fish larvae in the Leeuwin Current. Continental Shelf Research, 31(19-20), 20182040. https://doi.org/10.1016/j.csr.2011.10.006

Pecl, G. T., Araújo, M. B., Bell, J. D., Blanchard, J., Bonebrake, T. C., Chen, I.-C., Clark, T. D., Colwell, R. K., Danielsen, F., Evengård, B., Falconi, L., Ferrier, S., Frusher, S., Garcia, R. A., Griffis, R. B., Hobday, A. J., Janion-scheepers, C., Jarzyna, M. A., Jennings, S., ... Tuanmu, M.-N. (2017). Biodiversity redistribution under climate change: Impacts on ecosystems and human well-being. Science, 355(6332). https:// doi.org/10.1126/science.aai9214

Poloczanska, E. S., Brown, C. J., Sydeman, W. J., Kiessling, W., Schoeman, D. S., Moore, P. J., Brander, K., Bruno, J. F., Buckley, L. B., Burrows, M. T., Duarte, C. M., Halpern, B. S., Holding, J., Kappel, C. V., O'Connor, M. I., Pandolfi, J. M., Parmesan, C., Schwing, F., Thompson, S. A., \& Richardson, A. J. (2013). Global imprint of climate change on marine life. Nature Climate Change, 3(10), 919-925. https://doi.org/10.1038/nclimate1958

Rasher, D. B., Hoey, A. S., \& Hay, M. E. (2013). Consumer diversity interacts with prey defenses to drive ecosystem function. Ecology, 94(6), 1347-1358. https://doi.org/10.1890/12-0389.1

Reynolds, R. W., Smith, T. M., Liu, C., Chelton, D. B., Casey, K. S., \& Schlax, M. G. (2007). Daily high-resolution-blended analyses for sea surface temperature. Journal of Climate, 20(22), 5473-5496. https:// doi.org/10.1175/2007JCLI1824.1

Roxburgh, S. H., Shea, K., \& Wilson, J. B. (2004). The intermediate disturbance hypothesis: Patch dynamics and mechanisms of species coexistence. Ecology, 85(2), 359-371. https://doi. org/10.1890/03-0266

Ruttenberg, B. I., Adam, T. C., Duran, A., \& Burkepile, D. E. (2019). Identity of coral reef herbivores drives variation in ecological processes over multiple spatial scales. Ecological Applications, 29(4), e01893. https://doi.org/10.1002/eap.1893

Saunders, B. J., Kendrick, G. A., \& Harvey, E. S. (2015). Temperate territorial damselfish act like tropical damselfish, but have no measurable 
effect on algae within their feeding areas. Journal of Experimental Marine Biology and Ecology, 472, 107-118. https://doi.org/10.1016/j. jembe.2015.06.021

Shantz, A. A., Ladd, M. C., \& Burkepile, D. E. (2020). Overfishing and the ecological impacts of extirpating large parrotfish from Caribbean coral reefs. Ecological Monographs, 90(2), e01403. https://doi. org/10.1002/ecm.1403

Siqueira, A. C., Bellwood, D. R., \& Cowman, P. F. (2019). The evolution of traits and functions in herbivorous coral reef fishes through space and time. Proceedings of the Royal Society B: Biological Sciences, 286(1897), 20182672. https://doi.org/10.1098/rspb.2018.2672

Smale, D. A., Wernberg, T., Oliver, E. C. J., Thomsen, M., Harvey, B. P., Straub, S. C., Burrows, M. T., Alexander, L. V., Benthuysen, J. A., Donat, M. G., Feng, M., Hobday, A. J., Holbrook, N. J., PerkinsKirkpatrick, S. E., Scannell, H. A., Sen Gupta, A., Payne, B. L., \& Moore, P. J. (2019). Marine heatwaves threaten global biodiversity and the provision of ecosystem services. Nature Climate Change, 9(4), 306-312. https://doi.org/10.1038/s41558-019-0412-1

Smith, K. A., Dowling, C. E., \& Brown, J. (2019). Simmered then boiled: Multi-decadal poleward shift in distribution by a temperate fish accelerates during marine heatwave. Frontiers in Marine Science, 6, 407. https://doi.org/10.3389/fmars.2019.00407

Smith, S. M., Malcolm, H. A., Marzinelli, E. M., Schultz, A. L., Steinberg, P. D., \& Vergés, A. (2021). Tropicalization and kelp loss shift trophic composition and lead to more winners than losers in fish communities. Global Change Biology, 27(11), 2537-2548. https://doi. org/10.1111/gcb.15592

Steneck, R. S., Bellwood, D. R., \& Hay, M. E. (2017). Herbivory in the marine realm. Current Biology, 27(11), R484-R489. https://doi. org/10.1016/j.cub.2017.04.021

Streit, R. P., Cumming, G. S., \& Bellwood, D. R. (2019). Patchy delivery of functions undermines functional redundancy in a high diversity system. Functional Ecology, 33(6), 1144-1155. https://doi. org/10.1111/1365-2435.13322

Stuart-Smith, R. D., Edgar, G. J., Barrett, N. S., Kininmonth, S. J., \& Bates, A. E. (2015). Thermal biases and vulnerability to warming in the world's marine fauna. Nature, 528(7580), 88-92. https://doi. org/10.1038/nature16144

Stuart-Smith, R. D., Edgar, G. J., \& Bates, A. E. (2017). Thermal limits to the geographic distributions of shallow-water marine species. Nature Ecology and Evolution, 1(12), 1846-1852. https://doi.org/10.1038/ s41559-017-0353-x

Stuart-Smith, R. D., Mellin, C., Bates, A. E., \& Edgar, G. J. (2021). Habitat loss and range shifts contribute to ecological generalization among reef fishes. Nature Ecology \& Evolution, 5(5), 656-662. https://doi. org/10.1038/s41559-020-01342-7

Taylor, B. M., Benkwitt, C. E., Choat, H., Clements, K. D., Graham, N. A., \& Meekan, M. G. (2020). Synchronous biological feedbacks in parrotfishes associated with pantropical coral bleaching. Global Change Biology, 26(3), 1285-1294. https://doi.org/10.1111/gcb.14909

Tebbett, S. B., Morais, R. A., Goatley, C. H. R., \& Bellwood, D. R. (2021). Collapsing ecosystem functions on an inshore coral reef. Journal of Environmental Management, 289. https://doi.org/10.1016/j.jenvm an.2021.112471

Törnroos, A., Pecuchet, L., Olsson, J., Gårdmark, A., Blomqvist, M., Lindegren, M., \& Bonsdorff, E. (2019). Four decades of functional community change reveals gradual trends and low interlinkage across trophic groups in a large marine ecosystem. Global Change Biology, 25(4), 1235-1246. https://doi.org/10.1111/gcb.14552

Tuya, F., Wernberg, T., \& Thomsen, M. S. (2011). The relative influence of local to regional drivers of variation in reef fishes. Journal of Fish Biology, 79(1), 217-234. https://doi. org/10.1111/j.1095-8649.2011.03015.x

Venables, W. N., \& Ripley, B. D. (2002). Modern applied statistics with S. Springer.
Vergés, A., Doropoulos, C., Malcolm, H. A., Skye, M., Garcia-Pizá, M., Marzinelli, E. M., Campbell, A. H., Ballesteros, E., Hoey, A. S., VilaConcejo, A., Bozec, Y.-M., \& Steinberg, P. D. (2016). Long-term empirical evidence of ocean warming leading to tropicalization of fish communities, increased herbivory, and loss of kelp. Proceedings of the National Academy of Sciences of the United States of America, 113(48), 13791-13796. https://doi.org/10.1073/pnas.1610725113

Vergés, A., McCosker, E., Mayer-Pinto, M., Coleman, M. A., Wernberg, T., Ainsworth, T., \& Steinberg, P. D. (2019). Tropicalisation of temperate reefs: Implications for ecosystem functions and management actions. Functional Ecology, 33(6), 1000-1013. https://doi. org/10.1111/1365-2435.13310

Vergés, A., Steinberg, P. D., Hay, M. E., Poore, A. G. B., Campbell, A. H., Heck, K. L., Booth, D. J., Coleman, M. A., Feary, D. A., Figueira, W. Langlois, T., Marzinelli, E. M., Mizerek, T., Mumby, P. J., Nakamura, Y., Van Sebille, E., Gupta, A. S., Smale, D. A., Tomas, F., ... Wilson, S. K. (2014). The tropicalization of temperate marine ecosystems: Climate-mediated changes in herbivory and community phase shifts. Proceedings of the Royal Society B: Biological Sciences, 281(1789), 20140846. https://doi.org/10.1098/rspb.2014.0846

Vergés, A., Tomas, F., Cebrian, E., Ballesteros, E., Kizilkaya, Z., Dendrinos, P., Karamanlidis, A. A., Spiegel, D., \& Sala, E. (2014). Tropical rabbitfish and the deforestation of a warming temperate sea. Journal of Ecology, 102(6), 1518-1527. https://doi. org/10.1111/1365-2745.12324

Violle, C., Navas, M. L., Vile, D., Kazakou, E., Fortunel, C., Hummel, I., \& Garnier, E. (2007). Let the concept of trait be functional! Oikos, 116(5), 882-892. https://doi.org/10.1111/j.0030-1299.2007.15559.x

Wernberg, T., Bennett, S., Babcock, R. C., De Bettignies, T., Cure, K., Depczynski, M., Dufois, F., Fromont, J., Fulton, C. J., Hovey, R. K., Harvey, E. S., Holmes, T. H., Kendrick, G. A., Radford, B., SantanaGarcon, J., Saunders, B. J., Smale, D. A., Thomsen, M. S., Tuckett, C. A., ... Wilson, S. (2016). Climate-driven regime shift of a temperate marine ecosystem. Science, 353(6295), 169-172. https://doi. org/10.1126/science.aad8745

Wernberg, T., Coleman, M. A., Bennett, S., Thomsen, M. S., Tuya, F., \& Kelaher, B. P. (2018). Genetic diversity and kelp forest vulnerability to climatic stress. Scientific Reports, 8(1), 1-8. https://doi. org/10.1038/s41598-018-20009-9

Wernberg, T., Smale, D. A., Tuya, F., Thomsen, M. S., Langlois, T. J., de Bettignies, T., Bennett, S., \& Rousseaux, C. S. (2013). An extreme climatic event alters marine ecosystem structure in a global biodiversity hotspot. Nature Climate Change, 3(1), 78-82. https://doi. org/10.1038/nclimate1627

Wernberg, T., Thomsen, M. S., Tuya, F., \& Kendrick, G. A. (2011). Biogenic habitat structure of seaweeds change along a latitudinal gradient in ocean temperature. Journal of Experimental Marine Biology and Ecology, 400(1), 264-271. https://doi.org/10.1016/j.jembe.2011.02.017

Whalen, M. A., Whippo, R. D. B., Stachowicz, J. J., York, P. H., Aiello, E., Alcoverro, T., Altieri, A. H., Benedetti-Cecchi, L., Bertolini, C., Bresch, M., Bulleri, F., Carnell, P. E., Cimon, S., Connolly, R. M., Cusson, M., Diskin, M. S., D'Souza, E., Flores, A. A. V., Fodrie, F. J., ... Duffy, J. E. (2020). Climate drives the geography of marine consumption by changing predator communities. Proceedings of the National Academy of Sciences of the United States of America, 117(45), 28160-28166. https://doi.org/10.1073/pnas.2005255117

Zarco-Perello, S., Bosch, N. E., Bennett, S., Vanderklift, M. A., \& Wernberg, T. (2021). Persistence of tropical herbivores in temperate reefs constrain kelp resilience to cryptic habitats. Journal of Ecology, 109(5), 2081-2094. https://doi.org/10.1111/1365-2745.13621

Zarco-Perello, S., Carroll, G., Vanderklift, M., Holmes, T., Langlois, T. J., \& Wernberg, T. (2020). Range-extending tropical herbivores increase diversity, intensity and extent of herbivory functions in temperate marine ecosystems. Functional Ecology, 34(11), 2411-2421. https:// doi.org/10.1111/1365-2435.13662 
Zarco-Perello, S., Langlois, T. J., Holmes, T., Vanderklift, M. A., \& Wernberg, T. (2019). Overwintering tropical herbivores accelerate detritus production on temperate reefs. Proceedings of the Royal Society B: Biological Sciences, 286(1915), 20192046. https://doi. org/10.1098/rspb.2019.2046

Zarco-Perello, S., Wernberg, T., Langlois, T. J., \& Vanderklift, M. A. (2017). Tropicalization strengthens consumer pressure on habitat-forming seaweeds. Scientific Reports, 7(1), 1-8. https://doi.org/10.1038/ s41598-017-00991-2

Zinke, J., Rountrey, A., Feng, M., Xie, S.-P., Dissard, D., Rankenburg, K., Lough, J. M., \& McCulloch, M. T. (2014). Corals record long-term Leeuwin current variability including Ningaloo Niño/Niña since 1795. Nature Communications, 5(1), 1-9. https://doi.org/10.1038/ ncomms 4607

Zubia, M., Andréfouët, S., \& Payri, C. (2015). Distribution and biomass evaluation of drifting brown algae from Moorea lagoon (French Polynesia) for eco-friendly agricultural use. Journal of Applied Phycology, 27(3), 1277-1287. https://doi.org/10.1007/s1081 1-014-0400-9

\section{SUPPORTING INFORMATION}

Additional supporting information may be found in the online version of the article at the publisher's website.

How to cite this article: Bosch, N. E., McLean, M., ZarcoPerello, S., Bennett, S., Stuart-Smith, R. D., Vergés, A., Pessarrodona, A., Tuya, F., Langlois, T., Spencer, C., Bell, S., Saunders, B. J., Harvey, E. S., \& Wernberg, T. (2022).

Persistent thermally driven shift in the functional trait structure of herbivorous fishes: Evidence of top-down control on the rebound potential of temperate seaweed forests? Global Change Biology, 00, 1-16. https://doi. org/10.1111/gcb.16070 